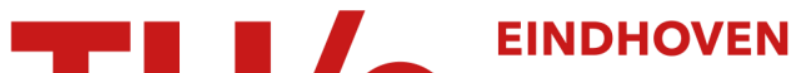 \\ UNIVERSITY OF \\ TECHNOLOGY
}

\section{Measuring financial contagion : a copula approach}

\section{Citation for published version (APA):}

Rodriguez, J. C. (2004). Measuring financial contagion : a copula approach. (Report Eurandom; Vol. 2004018).

Eurandom.

\section{Document status and date:}

Published: 01/01/2004

\section{Document Version:}

Publisher's PDF, also known as Version of Record (includes final page, issue and volume numbers)

\section{Please check the document version of this publication:}

- A submitted manuscript is the version of the article upon submission and before peer-review. There can be important differences between the submitted version and the official published version of record. People interested in the research are advised to contact the author for the final version of the publication, or visit the $\mathrm{DOI}$ to the publisher's website.

- The final author version and the galley proof are versions of the publication after peer review.

- The final published version features the final layout of the paper including the volume, issue and page numbers.

Link to publication

\section{General rights}

Copyright and moral rights for the publications made accessible in the public portal are retained by the authors and/or other copyright owners and it is a condition of accessing publications that users recognise and abide by the legal requirements associated with these rights.

- Users may download and print one copy of any publication from the public portal for the purpose of private study or research.

- You may not further distribute the material or use it for any profit-making activity or commercial gain

- You may freely distribute the URL identifying the publication in the public portal.

If the publication is distributed under the terms of Article 25fa of the Dutch Copyright Act, indicated by the "Taverne" license above, please follow below link for the End User Agreement:

www.tue.nl/taverne

Take down policy

If you believe that this document breaches copyright please contact us at:

openaccess@tue.nl

providing details and we will investigate your claim. 


\title{
Measuring Financial Contagion: A Copula Approach.
}

\author{
Juan Carlos Rodriguez ${ }^{*}$ \\ EURANDOM \\ (European Institute for Statistics, Probability, \\ Operations Research and their Applications)
}

This Draft:

December, 2003

\begin{abstract}
This paper studies financial contagion using a methodology that goes beyond the simple analysis of correlation breakdown, and, at the same time, is careful in the characterization of nonlinearity and asymptotic dependence. It also avoids discretion in the identification of the contagious episodes and in the definition of extreme outcomes. It accomplishes these objectives by the use of copulas with Markov switching parameters. Using daily returns of stock indices from five East Asian countries during the Asian Crisis, and from four Latin-American countries during the Mexican Crisis, I find evidence of changing dependence structures during periods of financial turmoil. Increased tail dependence and asymmetry in times of high volatility characterize the Asian countries, while symmetry and tail independence describe better the Latin-American case. This paper makes the case that structural breaks in tail dependence are a potentially important dimension of contagion. If contagion is a nonlinear phenomenon, as the results of this paper suggest, it is dangerous to consider, without further investigation, the rejection of the correlation breakdown hypothesis as evidence of a stable dependence structure.
\end{abstract}

Key Words: Financial Crises, Contagion, Copulas.

JEL Classification: G100, F3

\footnotetext{
*I am grateful to Raúl Susmel and seminar participants at EURANDOM for their comments and suggestions. Any remaining errors are my own. Address for correspondence: Eurandom, P.O Box 513, 5600 MB, Eindhoven, The Netherlands. TEL: +31 40 2478129. FAX: +31 40 2478190. Email: rodriguez@eurandom.tue.nl.
} 


\section{Introduction}

A central issue in asset allocation and risk management is whether financial markets become more interdependent during financial crises. This issue acquired dramatic importance during the five major crises of the 1990 's ${ }^{1}$. Common to all these episodes was the fact that the turmoil that originated in one market extended to a wide range of markets and countries in a way that was hard to explain on the basis of changes in fundamentals. The word "contagion" became popular, both in the press and in the academic literature, to refer to this phenomenon.

During the nineties, the study of financial contagion, defined in a recent influential paper ${ }^{2}$ as "a significant increase in cross-market linkages after a shock to one country (or group of countries)", was conducted mostly around the notion of "correlation breakdown": a statistically significant increase in correlation during the crash period. Examples of this literature are the works by Bertero and Mayer (1989) and King and Wadhwani (1990), who find evidence of an increase in the correlation of stock returns at the time of the 1987 crash. Also, Calvo and Reinhardt (1996) report correlation shifts during the Mexican crisis, while Baijn and Goldfajn (1999) find significant increases in correlation for several East-Asian markets and currencies during the East-Asian crisis.

The studies of contagion based on structural shifts in correlation were challenged by Boyer, Gibson and Loretan $(1999)^{3}$, who showed that tests for changes in correlation that not take into account conditional heteroskedasticity may be severely biased. Calculating the correlation between two random variables, conditioning on the extreme realizations of one of them, will likely suggest correlation breakdown, even if the true data generation process has constant correlation.Forbes and Rigobon (2002) generalized the approach of Boyer et al. (1999) and applied it to the study of three major crises (the 1987 crash, the Mexican devaluation, and the East-Asian crisis). After adjusting for heteroskedasticity, they could not find evidence of correlation breakdown in any of them. They concluded that contagion is nonexistent. The phenomenon that has been labeled as contagion is just

\footnotetext{
${ }^{1}$ These were the ERM attacks (1992), the Mexican devaluation (1994), the East Asian crisis (1997), the Russian default (1998), and the devaluation of the Brazilian real (1999).

${ }^{2}$ See Forbes and Rigobon (2002).

${ }^{3}$ See also Loretan and English (2000).
} 
the continuation in times of increased volatility of the strong dependence among international markets that exists in tranquil times.

In this way, by the end of the decade of 1990 the literature was far from having reached a consensus about the very existence of contagion. At this point, some authors began to recognize the necessity to go beyond the linear approach to address the issue. For example, Longin and Solnik (2001), Hartman, Straetmans and de Vries (2000) and Bae, Karolyi and Stulz (2001) presented models based on extreme value theory, while others, like Ramchand and Susmel (1999), Ang and Bekaert (2002) and Chesney and Jondeau (2000), explored Markov switching models. These works cope with the Forbes and Rigobon critique either by studying tail correlation (extreme value models), or by providing a consistent model to accommodate structural breaks in the variance (Markov switching models). An additional advantage of Markov switching models in the study of contagion is that they do not rely on an ad-hoc determination of the crisis period. As Dungey and Zhumabekova (2000) have shown, tests of contagion can be seriously affected by the size of the "crisis" and "non-crisis" periods.

Markov switching models have been limited to analyze the case of bivariate normality ${ }^{4}$. In this way, they have missed a potentially important dimension of the contagion phenomenon such as nonlinear dependence. As Bae et al. (2001) have pointed out: "The concerns (about contagion) are generally founded on the presumption that there is something different about extremely bad events that leads to irrational outcomes, excess volatility, and even panics. In the context of stock returns, this means that if panic grips investors as stock returns fall and leads them to ignore economic fundamentals, one would expect large negative returns to be contagious in a way that small negative returns are not"

On the other hand, models based on extreme value theory, even those that have tested for some form of nonlinearity, have implicitly assumed an asymptotically dependent structure. There are two forms of extreme value dependence for random variables: asymptotic dependence and asymptotic independence, and both allow for dependence between relatively large realizations of each variable. But to be asymptotically dependent, the random variables must be associated in the very tails of

\footnotetext{
${ }^{4}$ An exception is Ang and Chen (2003), who consider mixtures of normals.

${ }^{5}$ Bae, Karolyi and Stulz (2001), page 2. See also Longin and Solnik (2001) for a paper that addresses directly this issue.
} 
the distribution. In a recent paper, Poon, Rockinger and Tawn (2003) could not find evidence of asymptotic dependence in daily stock market returns for the US, Japan, Germany and France after filtering the series from GARCH effects. An important conclusion of this work is that assuming asymptotic dependence can lead to serious overestimation of financial risks. Another potential shortcoming of Extreme Value models is that there always exists discretion in defining what an extreme observation is 6 .

This paper studies financial contagion using a methodology that goes beyond the simple analysis of correlation breakdown, and, at the same time, is careful in the characterization of nonlinearity and asymptotic dependence. It also avoids discretion in the identification of the contagious episodes and in the definition of extreme outcomes. It accomplishes these objectives by the use of copulas with Markov switching parameters.

Nelsen defines copulas as "functions that join or couple multivariate distribution functions to their one-dimensional marginal distribution functions" (Nelsen, 1999, page 5). Copulas contain all the information about the dependence structure of a vector of random variables. They can capture nonlinear dependence among random variables, while correlation is only a linear measure of dependence. In particular, copulas contain information about the joint behavior of the random variables in the tails of the distribution ${ }^{7}$, which should be of primary interest in a study of contagion of financial crises ${ }^{8}$. Moreover, copulas are able to capture tail behavior without the need of using discretion to define extreme outcomes.

Copulas enable the modeler to construct flexible multivariate distributions exhibiting rich patterns of tail behavior, ranging from tail independence to tail dependence, and different kinds of asymmetry. They are an alternative to correlation in the modeling of financial risks. This is important in Finance, as correlation is the canonical measure of dependence only in the case of the multivariate normal distribution (or, more in general, of spherical and elliptical distributions), but there is

\footnotetext{
${ }^{6}$ For a critical assessment of extreme value theory in Finance, see Diebold, Schuerman and Stroughair (2000).

${ }^{7}$ Section 3 of this paper provides a short survey on copulas. For an introduction to copulas, see Nelsen (1999).

${ }^{8}$ Multivariate normality assumes tail independence, which is another reason to look for better models to study financial crises.
} 
mounting evidence that distributions in Finance are outside of this class ${ }^{9}$. Moreover, research in multivariate extreme value theory has shown that it is possible to construct multivariate distributions with identical correlations but otherwise completely different dependence structures.

Fitting copulas with different tail behavior makes it possible to test whether times of increased dependence can be also characterized by changes in one or both tails of the distribution. However, in order to capture shifts in the dependence structure, the copula that describes it must be time-varying. Patton (2001a, 2001b) pioneered the study of time-varying $\operatorname{copulas}^{10}$. He introduced the concept of conditional copula, and applied it to the study of asymmetries in the dependence structure of a set of exchange rates.

In this paper I explore whether financial crises can be described as periods of change in the dependence structure between markets. I model the dependence structure as a mixture of copulas ${ }^{11}$, with parameters changing over time according to a Markov switching model. I study two classes of copulas: a finite mixture of the Frank, Gumbel, and Clayton copulas ${ }^{12}$, which can capture asymmetries in tail dependence, and the bivariate Student $t$ copula, which exhibits symmetric tail dependence and has the tail independent Normal copula as a special case. With purposes of better comparison with the mixture, I also present results on the Frank copula, which, as the Normal, is symmetric and exhibits tail independence.

To identify the crisis episodes, I model the marginals using the SWARCH structure introduced by Hamilton and Susmel (1999). In a SWARCH model, the variance of the series under study is subject to occasional shifts, which are the outcome of a random variable that follows a Markov process. In this way, I can explore whether different dependence structures are associated to different variance regimes. In the mixture, the shifting parameters of the dependence structure are the weights. Otherwise, the remaining parameters of the mixture are assumed constant ${ }^{13}$. In the Student copula, the changing parameters are the correlation coefficient and the

\footnotetext{
${ }^{9}$ For an analysis of the shortcomings of the use of correlation as the main measure of dependence in finance and insurance, see Embrechts et al. (1999).

${ }^{10}$ See also Rockinger and Jondeau (2001).

${ }^{11}$ Mixtures of copulas are copulas. See Nelsen (1999). Finite mixtures of distributions are discussed in Hamilton (1994) in the context of Markov switching Models. See also Everitt and Hand (1981).

${ }^{12}$ The Frank copula exhibits tail independence, while the Gumbel and Clayton copulas exhibit upper and lower tail dependence, respectively. See Section three for a detailed description of these copulas.

${ }^{13}$ Under these assumptions I can construct parsimonious models in which the change in the dependence structure is captured by the shift in only one parameter.
} 
degrees of freedom. The Frank copula has only one parameter, which is allowed to switch between regimes.

This paper is related to Patton (2001a, 2001b) and Rockinger and Jondeau (2001) in that it models dependence using copulas with time-varying parameters. But unlike these authors, I also allow the parameters of the copula to change with the states of the variance to identify shifts in the dependence structure in times of crisis. In order to do this, I build a multivariate SWARCH model on the lines of Ramchand and Susmel (1999). The key difference with Ramchand and Susmel (1999) is that I model the dependence structure using switching copulas instead of assuming bivariate normality. A switching copula can capture increases in tail dependence, reflecting that, for example, the probability of markets crashing together is higher in periods of financial turmoil, while a model based on multivariate normality imposes tail independence. This is the first paper that uses "switching copulas" to study contagion of financial crises.

Using daily returns on stock indices from five East Asian countries (Thailand, Malaysia, Indonesia, Korea and Philippines), during the Asian Crisis, and from four Latin-American countries (Mexico, Argentina, Brazil and Chile) during the Mexican Crisis, I find evidence of changing dependence structures during periods of financial turmoil. I also test whether these changes are best described using copulas with tail dependence and asymmetry compared to symmetric and also to tail independent copulas. Increased tail dependence and asymmetry in times of high volatility characterize the Asian countries, while increased dependence with symmetry and tail independence describes Mexico-Brazil. Mexico-Argentina and Mexico-Chile are the only cases in which a stable dependence structure could not be rejected.

These results contribute to the ongoing debate on the existence of contagion. They show that times of financial turmoil are indeed times of increased dependence. Most cases studied in this paper exhibit contagion in the sense of Forbes and Rigobon's (2002) definition. However, although overall dependence increases, patterns of tail dependence change differ widely across markets. The cases of Thailand-Indonesia and Thailand-Korea, in which a tail independent structure is found in the tranquil period, while a tail dependent and asymmetric structure characterizes the crisis time suggest that the prevalence of tail independence found by Poon et al. (2002) may not be general. On this regard, excessive reliance on tail independence, although harmless in stable times, may lead to potentially serious 
underestimation of financial risks in periods of crisis. From an asset allocation perspective, recent results by Ang and Bekaert (2002) and Das an Uppal (2003) on portfolio selection establish that the costs of ignoring regime shifts can be substantial, especially in the presence of highly correlated jumps between markets.

The organization of the paper is the following. Section 2 presents the data and shows descriptive statistics. Section 3 presents univariate results for the SWARCH model, exploring whether the variances of the series studied are state dependent. Section 3 gives a short summary of copulas. Section 4 and 5 present results for the Asian and Mexican crises, respectively. Section 6 concludes. An appendix at the end of the paper provides tests on the specification of the copulas.

\section{Data}

This paper uses daily data (in US dollars) of stock indices from five Asian countries: Thailand, Malaysia, Indonesia, Korea and Philippines. The series go from 1/1/96 to 30/6/98 (652 observations). Also, four Latin-American countries are studied (Mexico, Argentina, Brazil and Chile), the series going from 1/1/93 to 31/12/95 (781 observations). Only regional contagion is considered. The variable of interest is daily returns, which are calculated as 100 times the difference in the log of the indices. All data come from Datastream. Table 1a shows descriptive statistics of the series. The non-normality of the data is apparent from the coefficients of skewness and kurtosis. Also, the Jarque-Bera test (reported in the last line of the table) strongly rejects normality ${ }^{14}$. Results from Latin-American markets (Table 1b) exhibit a similar pattern.

\footnotetext{
${ }^{14}$ Under the null of normality, the Jarque-Bera test statistics follows a chi-squared distribution with two degrees of freedom.
} 


\section{Copulas}

Copulas are "functions that join or couple multivariate distribution functions to their one-dimensional marginal distribution functions" $" 15$. The most important result in copula theory is Sklar's theorem:

Theorem 3.1 (Sklar, 1959): Let $D$ be an n-dimensional distribution function with margins $F_{1}, \ldots, F_{n}$. Then there exists an $n$-copula $C$ such that for al $\boldsymbol{x}$ in $\overline{\mathfrak{R}}^{n}$,

$$
D\left(x_{1}, \ldots, x_{n}\right)=C\left(F_{1}\left(x_{1}\right), \ldots, F_{n}\left(x_{n}\right)\right) .
$$

If $F_{1}, \ldots, F_{n}$ are all continuous, then $C$ is uniquely determined on $\operatorname{RanF}_{1} \times \ldots \times \operatorname{RanF}_{n}$. Conversely, if $C$ is an n-copula and $F_{1}, \ldots, F_{n}$ are distribution functions, the function $D$ defined above is an n-dimensional distribution function with margins $F_{1}, \ldots, F_{n} .{ }^{16}$

Therefore, if $D$ is a continuous multivariate distribution function, Sklar's theorem says that it is possible to separate the univariate margins from the dependence structure. The dependence structure is represented by the copula. This can be seen even more clearly if we assume the $F_{i}$ 's are differentiable, and $C$ and $D$ are ntimes differentiable. Then, deriving both sides of (1) to get the density of $D$, we get:

$$
\frac{\partial^{n} D\left(x_{1}, \ldots, x_{n}\right)}{\partial x_{1} \ldots \partial x_{2}}=\frac{\partial^{n} C\left(F_{1}\left(x_{1}\right), \ldots, F_{n}\left(x_{n}\right)\right)}{\partial x_{1} \ldots \partial x_{2}} \times f_{1}\left(x_{1}\right) \times \ldots \times f_{n}\left(x_{n}\right)
$$

That is, the density of $D$ has been expressed as the product of the copula density and the univariate marginal densities. It is in this sense that we say that the copula has all the information about the dependence structure.

Copulas have certain properties that are very useful in the study of dependence. First, copulas are invariant to strictly increasing transformations of the random variables. Second, widely used measures of concordance ${ }^{17}$ between random

\footnotetext{
${ }^{15}$ Nelsen (1999).

${ }^{16}$ For a proof, see Nelsen (1999).

${ }^{17}$ Nelsen's (1999) informal definition of concordance:"Two random variables X and Y are concordant if "large" values of X tend to be associatied with "large" values of $Y$, and "small" values of X tend to be associated with "small" values of Y. For a forma treatment, see Nelsen (1999), and also Joe (1997).
} 
variables, like Kendall's tau and Spearman's rho, are properties of the copula. Third, and of the greatest importance in the study of financial contagion, asymptotic tail dependence is also a property of the copula.

In what follows I provide formal definitions of asymptotic tail dependence and of a concordance measure, Kendall's tau, which will be widely used in the rest of the paper.

Intuitively, asymptotic tail dependence is a measure of the propensity of markets to crash (or boom) together. More formally ${ }^{18}$, let $(X, Y)$ be a vector of continuous random variables with marginal distribution functions $F$ and $G$. Let $u=$ $F(X)$, an $v=G(Y)^{19}$. The coefficient of upper tail dependence of $(X, Y)$ is:

$$
\lim _{u \uparrow 1} I P\left\{Y>G^{-1}(u) \mid X>F^{-1}(u)\right\}=\lambda_{U}
$$

The coefficient of upper tail dependence can be expressed in terms of the copula between $X$ and $Y$ as follows:

Definition 3.1: If a bivariate copula $C$ is such that:

$$
\lim _{u \uparrow 1} \frac{1-2 u+C(u, u)}{1-u}=\lambda_{U}
$$

exists, then $C$ has upper tail dependence if $\lambda_{U} \in(0,1]$, and upper tail independence if $\lambda_{U}=0$.

In the same way, the coefficient of lower tail dependence can be defined as:

$$
\lim _{u \downarrow 0} I P\left\{Y<G^{-1}(u) \mid X<F^{-1}(u)\right\}=\lambda_{L} .
$$

And, in terms of copulas:

Definition 3.2: If a bivariate copula $C$ is such that:

\footnotetext{
${ }^{18}$ This is based on Embrechts et al. (2001).

${ }^{19}$ It is a known theorem in Statistics that $u$ and $v$ are uniformly distributed in $[0,1]$.
} 


$$
\lim _{u \downarrow 0} \frac{C(u, u)}{u}=\lambda_{L}
$$

exists, then $C$ has lower tail dependence if $\lambda_{L} \in(0,1]$, and lower tail independence if $\lambda_{L}=0$.

Kendall's tau is a measure of concordance between random variables. Two points $\left(x_{1}, x_{2}\right),\left(y_{1}, y_{2}\right)$ in $\operatorname{IR}^{2}$ are said to be concordant if $\left(x_{1}-y_{1}\right)\left(x_{2}-y_{2}\right)>0$, and to be discordant if $\left(x_{1}-y_{1}\right)\left(x_{2}-y_{2}\right)<0$. In a similar two random vectors $\left(X_{1}, X_{2}\right)$, $\left(\tilde{X}_{1}, \tilde{X}_{2}\right)$ are said to be concordant if $I P\left[\left(X_{1}-\tilde{X}_{1}\right)\left(X_{2}-\tilde{X}_{2}\right)>0\right]-I P\left[\left(X_{1}-\tilde{X}_{1}\right)\left(X_{2}-\tilde{X}_{2}\right)<0\right]>0$, that is, if $X_{1}$ tends to increase with $X_{2}$, and discordant otherwise. Kendall's tau measures this difference of probabilities:

$$
\rho_{\tau}\left(X_{1}, X_{2}\right)=I P\left[\left(X_{1}-\widetilde{X}_{1}\right)\left(X_{2}-\tilde{X}_{2}\right)>0\right]-I P\left[\left(X_{1}-\widetilde{X}_{1}\right)\left(X_{2}-\tilde{X}_{2}\right)<0\right] .
$$

It is possible to express Kendall's tau in term of the copula that joins $X_{1}$ with $X_{2}$ :

$$
\rho_{\tau}\left(X_{1}, X_{2}\right)=4 \iint_{[0,1]^{2}} C\left(u_{1}, u_{2}\right) d C\left(u_{1}, u_{2}\right)-1 .
$$

As a measure of concordance based on copulas, which means that it is invariant to increasing transformations of its arguments, Kendall's tau can capture nonlinear dependences that are not possible to measure with linear correlation. As contagion is most likely a nonlinear phenomenon, Kendall's tau will be the main measure of association studied in this paper.

Many copulas have been studied in the literature ${ }^{20}$. Because of their properties, three of them are becoming widely used in Finance and Insurance. These are the Gumbel, Clayton, Frank, and Student copulas. I summarize their properties below:

\footnotetext{
${ }^{20}$ For a catalog of copulas and their properties, see Nelsen (1999), and also Joe 1997).
} 


\section{A. Gumbel copula:}

$$
C_{G}(u, v ; \delta)=\exp \left\{-\left[(-\ln u)^{\delta}+(-\ln v)^{\delta}\right]^{\frac{1}{\delta}}\right\}, \quad \delta \in[1, \infty)
$$

This copula is characterized by lower tail dependence and upper tail independence. Its main properties are:

1) $\delta=1$ implies

$$
C_{G}(u, v ; 1)=u v
$$

the independent copula.

2) As $\delta \rightarrow \infty, C_{C l}(u, v ; \theta) \rightarrow \min (u, v)$. This limit is the upper Frèchet-Hoeffding bound. It can be shown that if $U$ and $V$ are two random variables uniformly distributed in $(0,1)$ with copula equal to $\min (u, v)$, then $I P(U=V)=1$.

3) Lower Tail Dependence: $\lambda_{L}=0$.

4) Upper Tail Dependence: $\lambda_{U}=2-2^{-\frac{1}{\delta}}$.

5) Kendall's $\tau: 1-\frac{1}{\delta}$.

\section{B. Clayton Copula:}

$$
C_{C l}(u, v ; \theta)=\left\{u^{-\theta}+v^{-\theta}-1\right\}^{-\frac{1}{\theta}}, \quad \theta \geq 0 .
$$

This copula is characterized by upper tail dependence and lower tail independence. Its main properties are:

1) $\theta \rightarrow 0$ implies

$$
C_{C l}(u, v ; \downarrow 0)=u v,
$$

the independent copula.

2) As $\theta \rightarrow \infty$, the upper Frèchet-Hoeffding bound is attained.

3) Lower Tail Dependence: $\lambda_{L}=2^{-\frac{1}{\theta}}$.

4) Upper Tail Dependence: $\lambda_{U}=0$.

5) Kendall's $\tau: \frac{\theta}{\theta+2}$. 


\section{Frank Copula:}

$$
C_{F}(u, v ; \alpha)=-\frac{1}{\alpha} \ln \left(1+\frac{\left(e^{-\alpha u}-1\right)\left(e^{-\alpha v}-1\right)}{e^{-\alpha}-1}\right), \quad \alpha \in I R .
$$

This copula is characterized by upper and lower tail independence. Its main properties are:

1) $\alpha \rightarrow 0$ implies

$$
C_{\alpha}(u, v ; \downarrow 0)=u v,
$$

the independent copula.

2) As $\theta \rightarrow \infty$, the upper Frèchet-Hoeffding bound is attained.

3) Lower Tail Dependence: $\lambda_{L}=0$.

4) Upper Tail Dependence: $\lambda_{U}=0$.

5) Kendall's $\tau: 1-\frac{4}{\alpha}\left(1-\int_{0}^{\alpha} \frac{t}{e^{t}-1} d t\right)$.

Note that the Frank copula implies asymptotic tail independence ${ }^{21}$, while the Clayton and Gumbel copulas imply dependence in one of the tails, but not in the other. Intuitively, this means that Clayton assigns more probability mass to events in the left tail (markets crash together), Gumbel assigns more probability mass to events in the right tail (markets boom together), and Frank is symmetric, assigning zero probability to events that are deep in the tails. Figure 1 shows the scatter plots of four simulated bivariate copulas: Gumbel (left-top panel), Clayton (right-top panel), Frank (left-bottom panel) and Student ${ }^{22}$ (right-bottom panel). In all cases, 1000 observations were generated, and margins were selected as standard normal. The parameters of the copulas were chosen to give a Kendall's tau equal to 0.3 . Therefore, the simulated random variables in Figure 1 differ only on the dependence structure, with the Clayton copula showing strong association in the left tail, while the Gumbel copula shows strong association in the right tail. It is in this sense that the Clayton and

\footnotetext{
${ }^{21}$ This does not imply independence. Actually, for the Frank copula, concordance increases with $\alpha$ (when $\alpha$ is positive).

${ }^{22}$ The Student copula is described in section E.
} 
Gumbel copulas describe asymmetric dependence. On the other hand, no clear association in the tails can be observed for the Frank copula.

As returns can exhibit dependence in both tails, it would be useful to have a copula that mingles both Clayton and Gumbel. This copula exists, and is known as the Clayton-Gumbel copula ${ }^{23}$. Its properties are:

\section{Clayton-Gumbel Copula:}

It is a two parameter copula, of the form:

$$
C_{C G}(u, v ; \theta, \delta)=\left\{1+\left[\left(u^{-\theta}-1\right)^{\delta}+\left(v^{-\theta}-1\right)^{\delta}\right]^{\frac{1}{\delta}}\right\}^{-\frac{1}{\theta}}, \quad \delta \geq 1, \theta \geq 0 .
$$

Properties:

1) $\delta=1$ implies:

$$
C_{C G}(u, v ; \theta, 1)=\left\{u^{-\theta}+v^{-\theta}-1\right\}^{-\frac{1}{\theta}},
$$

the Clayton Copula.

2) $\theta \rightarrow \infty$ implies:

$$
C_{C G}(u, v ; 0 \downarrow, \delta)=\exp \left\{-\left[(-\ln u)^{\delta}+(-\ln v)^{\delta}\right]^{\frac{1}{\delta}}\right\},
$$

the Gumbel copula.

3) Lower tail dependence: $\lambda_{L}=2^{-\frac{1}{\delta \theta}}$

4) Upper tail dependence: $\lambda_{U}=2-2^{-\frac{1}{\delta}}$

5) As $\theta \rightarrow 0$ and $\delta \rightarrow 1$ the independent copula obtains.

As $\theta \rightarrow \infty$ and $\delta \rightarrow \infty$, the upper Frèchet-Hoeffding bound is attained.

6) Kendall's $\tau: \frac{(2+\theta) \delta-2}{(2+\theta) \delta}$.

${ }^{23}$ See Joe (1997). 


\section{E. Student t Copula:}

It is a two-parameter copula that is constructed from the Student bivariate distribution using directly Sklar's theorem. With respect to the bivariate Student distribution, the copula has the additional flexibility that the marginals do not have to be Student with the same degrees of freedom. The t-copula with $v$ degrees of freedom and correlation $\rho$ is written as:

$$
C(u, v ; v, \rho)=\int_{\infty}^{t_{v}^{-1}(u)} \int_{\infty}^{t_{v}^{-1}(v)} \frac{1}{2 \pi \sqrt{\left(1-\rho^{2}\right)}}\left\{1+\frac{s^{2}-2 \rho s t+t^{2}}{v\left(1-\rho^{2}\right)}\right\}^{-\frac{v+1}{2}} d s d t .
$$

The t-copula is symmetric and exhibits tail dependence. The coefficient of tail dependence is:

$$
\left.\lambda_{L}=\lambda_{U}=2 \mid 1-t_{v+1}(\sqrt{(v+1)(1-\rho) /(1+\rho)})\right],
$$

where $t_{v+1}$ is a standard univariate $t$ distribution with $v+1$ degrees of freedom. Note that two random variables with copula $C(u, v ; v, \rho)$ can be asymptotically tail dependent even in the extreme case in which they are uncorrelated. In particular, for a copula with zero correlation and four degrees of freedom, the coefficient of tail dependence is equal to 0.08 . Zero correlation, and also $v \rightarrow \infty$, is necessary to get independence. As $v \rightarrow \infty$, with $\rho \neq 0$, the normal copula, and therefore tail independence, obtains. Kendall's tau is related to the correlation coefficient through the formula:

$$
\tau=\frac{2}{\pi} \arcsin (\rho)
$$

The right-bottom panel of Figure 1 shows a scatter plot of 1000 simulated observations belonging to a Student t copula with 3 degrees of freedom. Margins were selected as standard normal, and the correlation coefficient was chosen to give a Kendall's tau equal to 0.3 . Symmetry and tail dependence are patent in the strong association in both the right and left tails. 


\section{Univariate Results}

The models for the marginal distributions are based on the SWARCH model of Hamilton and Susmel (1994). In this section I show results that document the presence of different variance regimes in the series analyzed in this paper.

The general formulation of an $\operatorname{AR}(p)-G A R C H(q, r)$ model for the stochastic process $y_{t}$ is:

$$
y_{t}=\mu+\sum_{i=1}^{p} \phi_{i} y_{t-i}+u_{t},
$$

where:

$$
u_{t}=\sqrt{h_{t}} v_{t}
$$

and:

$$
h_{t}=\alpha_{0}+\sum_{i=1}^{q} \alpha_{i} u_{t-i}^{2}+\sum_{i=1}^{r} \beta_{i} h_{t-i} .
$$

The distribution of the residual $v_{t}$ has in general been assumed standard normal, although the usefulness of the standardized Student-t is also well documented in the literature $^{24}$, especially to deal with heavy-tailed, high frequency data of financial returns.

One shortcoming of ARCH models is that they are not well suited to describe structural breaks in the variance. Moreover, some authors have suggested that structural breaks are the reason of the high persistence found in ARCH models (see Lamoreaux and Lastrapes (1990)).

As a way to introduce regime switches in variance, Hamilton and Susmel $(1994)^{25}$ presented the Switching ARCH (SWARCH) model, in which the residual $u_{t}$ in equation (1) is modelled as:

$$
u_{t}=\sqrt{g_{s t}} \times \bar{u}_{t}
$$

and $\bar{u}_{t}$ follows a standard $\mathrm{ARCH}(\mathrm{q})$ process:

$$
\bar{u}_{t}=\sqrt{h_{t}} v_{t}
$$

\footnotetext{
${ }^{24}$ Another popular distribution is the GED. For a comprehensive survey of ARCH models, see Bollerslev (1994).

${ }^{25}$ There is also a contribution by Cai (1994).
} 
where $h_{t}$ obeys:

$$
h_{t}=\alpha_{0}+\alpha_{1} \bar{u}_{t-1}^{2}+\alpha_{2} \bar{u}_{t-2}^{2}+\ldots+\alpha_{q} \bar{u}_{t-q}^{2}
$$

From equations (2) and (3), we see that the level of the variance can occasionally change, depending on the values of $g_{s t}$, the scaling parameter. The variable $s_{t}$ in equation (2) is assumed to take values $1,2, \ldots, \mathrm{K}$, and to be described as a Markov Chain:

$$
P=\left[\begin{array}{cccc}
p_{11} & p_{21} & \cdots & p_{k 1} \\
p_{12} & p_{22} & \cdots & p_{k 2} \\
\cdots & \cdots & \cdots & \cdots \\
p_{1 k} & p_{2 k} & \cdots & p_{k k}
\end{array}\right]
$$

The variable $s_{t}$ is regarded as the "state" or "regime" that the process is in at date $t$. So, a SWARCH $(\mathrm{K}, \mathrm{q})$ is a model in which the variable $s_{t}$ can be in any K possible states at time $\mathrm{t}$, and $\mathrm{q}$ is the number of lags in the conditional variance.

Hamilton (1989) describes how to estimate the parameters in (2) through the maximization of a likelihood function, and also how to do inference about the state in which the process has been at date $t$. Inferences based on information up to time $t$ are called "filtered probabilities", while inferences based on information from the full sample are called "smoothed probabilities"26.

The model selected to investigate the presence of different volatility regimes in the markets considered in this paper, is a $\operatorname{SWARCH}(2,1)$. Although the selection of the number of states and lags has been based on practical reasons of avoiding overparameterization and cumbersome computation in the multivariate $\operatorname{case}^{27}$, specification tests on the copulas reported in the appendix suggest that the AR(1)$\operatorname{SWARCH}(2,1)$ describes well the structure of the marginals.

Therefore, I model returns in country $i$ as:

$$
y_{t}^{i}=\mu+\phi y_{t-1}^{i}+u_{t}^{i}
$$

where:

\footnotetext{
${ }^{26}$ This methodology is described in Hamilton (1994). See also the original papers: Hamilton (1989), and Hamilton and Susmel (1994).

${ }^{27}$ Adding just one more state for the variance would imply to estimate eighteen additional parameters in the bivariate model.
} 


$$
u_{t}^{i}=\sqrt{g_{s t}^{i}} \times \bar{u}_{t}^{i}
$$

and $\bar{u}_{t}^{i}$ follows a standard $\mathrm{ARCH}(\mathrm{q})$ process:

$$
\bar{u}_{t}^{i}=\sqrt{h_{t}^{i}} v_{t}^{i}
$$

where $h_{t}^{i}$ obeys:

$$
h_{t}^{i}=a_{t}^{i}+a_{1}^{i 2} \bar{u}_{t-1}^{i 2}
$$

The residual $v_{t}^{i}$ is assumed to have a Student-t distribution with $n$ degrees of freedom, which must also be estimated.

Table 2 shows univariate results for five Asian markets: Thailand, Malaysia, Indonesia, Phillipines, and Korea. Note that, in all cases, the variance in the highvolatility state is far higher than the one in the low volatility state (from 7 times higher in the case of Thailand, to 26 times higher in the case of Indonesia). The scaling variable $g$ is always significantly different from 1 , even at the $1 \%$ level. Also, all markets exhibit positive autocorrelation. Asian markets (with the exception of Korea) exhibit strong ARCH effects, together with Mexico and Chile. However, even in the countries exhibiting strong ARCH effects, the persistence of the variance is low. This is consistent with the remark made by Lamoreaux and Lastrapes (1990) that the high persistence found in ARCH models is due to structural breaks. The estimated degrees of freedom are also significantly higher than 2. Smooth probabilities (Figure 2) show that Thailand was the first country to enter in the high-variance regime $(5 / 12 / 1997)$, while Korea entered the last (9/26/1997). Results for Latin-American countries are similar. Interestingly, smooth probabilities (Figure 4) show that, in the Mexican crisis, all countries entered into the high-volatility state almost simultaneously, with Mexico leading the other countries, as expected. From the smooth probabilities, Mexico entered into the high volatility state on December 19, 1994. Interestingly, this is the same day that Forbes and Rigobon (2002) define as the start of the turmoil period in their paper. Mexico stayed in the high volatility period during 72 days. Argentina and Brazil entered into the high volatility state on December 20. Argentina remained in that state until June 29, 1995, and Brazil until April 4, 1995.

Table 2 and 3 also show empirical Kendal's tau between the originator and the country in the corresponding column, calculated from the residuals in both the low 
and high variance states. In all cases, the change in Kendall's tau shows that times of financial turmoil are also times of increased dependence. In the Asian case, the range of Kendall's tau increases goes from 50\% (Thailand-Malaysia) to 465\% (ThailandKorea). In the Latin-American case, it goes from 56\% (Mexico-Argentina) to $122 \%$ (Mexico-Brazil and Mexico-Chile). The significance of these changes will be analyzed in the next section.

In the cases of Thailand, Malaysia and Indonesia, the maximum-likelihood estimates of the transition probabilities of the high-variance state turn to be one. In this case I follow Hamilton and Lin (1996) and impose the value of one with the purpose of calculating the standard errors of the remaining parameters.

Also, it is important to note that, in the Asian case, countries are simultaneously in the high variance state during approximately $40 \%$ of the sample (see Figure 3), while in the Latin-American case countries are simultaneously in the high variance state during approximately $10 \%$ of the sample (see Figure 2 ).

In tables 2 and $3 \mathrm{LF}$ is the value of the maximized log-likelihood of the SWARCH $(2,1)$ model, while LF* is the value of the maximized log-likelihood under the restriction that there is only one state (this is equivalent to estimate an $\mathrm{ARCH}(1)$ model) . Although a standard likelihood-ratio test is not appropriate, because under the null hypothesis of no regime change the parameters of the high variance regime are not identified, I still provide the p-values of such a test in both tables for each country. The extremely small p-values obtained should be considered as fairly convincing evidence of regime switching ${ }^{28}$. Formal tests (see Hansen (1992)) are computationally cumbersome and will be provided in future versions of this paper.

\section{Bivariate Results}

Following Ramchand and Susmel (1998), I consider only the bivariate case to keep the models tractable for estimation. However, given that each univariate series can be in one of two variance regimes, the bivariate case will be a Markov switching Model with four states. For example, two countries, Malaysia and Thailand, will be at one of four states $s_{t}$ at time $t$ :

\footnotetext{
${ }^{28}$ Hamilton and Lin (1996) discuss informal tests of regime switching.
} 
$s_{t}=1$ : Malaysia, Low volatility; Thailand, Low volatility.

$s_{t}=2$ : Malaysia, High volatility; Thailand, Low volatility.

$s_{t}=3$ : Malaysia, Low volatility; Thailand, High volatility.

$s_{t}=4$ : Malaysia, High volatility; Thailand, High volatility.

I also follow Ramchand and Susmel (1998) in considering one of the countries as the generator of the turmoil. For the Asian crisis, that country is Thailand. Thailand was the first Asian country to be hit in the process that led to the Asian crisis. It was also the first country to enter into the high volatility state in the sample. I will further assume that the dependence structure can change only between states 1 and 2 (Thailand's low volatility states) and 3 and 4 (Thailand's high volatility states). For obvious reasons, Mexico will be considered the generator country in the LatinAmerican case, and I assume that the dependence structure between Latin-American markets can change only between the high and low volatility states of Mexico.

As it was shown in Section 3, a bivariate density can be decomposed as the product of the copula and the univariate marginals. This is very convenient in maximum-likelihood estimation, because it permits to estimate the parameters of the density in two steps: first the parameters of the marginals, and then the parameters of the copula. However, when the copula and marginal parameters change simultaneously according to a Markov switching process, the two-step approach is no longer useful, and all parameters must be estimated simultaneously. Assuming a twostate Markov Chain for each country, the likelihood of each observation can be written as:

$$
\begin{aligned}
& q_{t}\left(x_{t}, y_{t} \mid I_{t-1} ; \Theta\right)= \\
& \quad \sum_{S_{t}} \sum_{S_{t-1}} f_{t}\left(x_{t} \mid S_{t}, S_{t-1}, I_{t-1} ; \Theta\right) \times g_{t}\left(y_{t} \mid S_{t}, S_{t-1}, I_{t-1} ; \Theta\right) \times C_{12}\left(u_{t}, v_{t} \mid S_{t}, S_{t-1}, I_{t-1} ; \Theta\right) \times P\left(S_{t}, S_{t-1} \mid I_{t-1} ; \Theta\right),
\end{aligned}
$$

where $P\left(S_{t}, S_{t-1} \mid I_{t-1} ; \Theta\right)$ is the probability of the states conditional on past information. $f, g$ and $C_{12}$ are the marginals and copula densities, respectively, $\Theta$ is a vector of parameters, and $u_{t}=F_{x}\left(x_{t} \mid S_{t}, S_{t-1}, I_{t-1} ; \theta\right), v_{t}=F_{y}\left(y_{t} \mid S_{t}, S_{t-1},, I_{t-1} ; \theta\right)$. Then, the likelihood function to be maximized is: 


$$
L(\theta)=\sum_{t=1}^{T} \log \left[q\left(x_{t}, y_{t} \mid I_{t-1}, \theta\right)\right]
$$

To find the copula that best fits the data I estimated three models: 1) a mixture of Frank, Clayton and Gumbel, 2) the Frank copula with switching parameter, and 3) the Student $t$ copula with switching correlation and degrees of freedom. The mixture (model 1) admits asymptotic tail dependence and asymmetry, while the Frank copula (model 2) is symmetric and exhibits tail dependence. The Student t copula (model 3) is also symmetric and has the property of asymptotic tail dependence. The normal copula obtains as a special case of the Student copula as the degrees of freedom go to infinity. Having a model that includes normality makes the Frank copula somewhat redundant. Nevertheless, I include results on the Frank copula to facilitate comparison with the mixture.

In model 1, to find the "right" mixture I first estimated, for all cases, a combination of the three copulas (Clayton, Gumbel, Frank ):

$$
\begin{aligned}
& C(u, v ; \theta, \delta, \alpha)=\pi_{C S_{t}} C_{C}(u, v ; \theta)+\pi_{G s_{t}} C_{G}(u, v ; \delta)+\left(1-\pi_{C s_{t}}-\pi_{G s_{t}}\right) C_{F}(u, v ; \alpha), \\
& 0 \leq \pi_{i s_{t}} \leq 1, i=C, G .
\end{aligned}
$$

where $\pi_{C_{s}}$ is the weight of the Clayton copula, $\pi_{G_{s}}$ is the weight of the Gumbel copula, and $\pi_{F_{s}}=1-\pi_{C_{s}}-\pi_{G_{s}}$ is the weight of the Frank copula. Note that the weights depend on the states: this is the way in which I try to capture changes in tail dependence. For example, after an increase in $\pi_{C_{s}}$, the copula will have more probability mass in the left tail.

In the Thailand-Malaysia case $\hat{\pi}_{F s_{t}}$ reached the boundary of zero, so the mixture estimated was Clayton, Gumbel:

$$
C_{C}^{G}(u, v ; \delta, \theta)=\pi_{s_{t}} C_{C}(u, v ; \theta)+\left(1-\pi_{s_{t}}\right) C_{G}(u, v ; \delta), \quad 0 \leq \pi_{s_{t}} \leq 1
$$

Note that here $\pi_{s_{t}}$ is the only shifting parameter. Lower tail dependence increases (and upper tail dependence decreases) as $\pi_{s_{t}}$ goes from zero to one. 
In the remaining Asian cases, all three copulas were found significant, with the weights of Clayton and Gumbel increasing from the low variance to the high variance state. This means that both lower and upper tail dependence increase in the crisis period. Note that a mixture of only two copulas (Frank and Clayton-Gumbel) can capture the implied change in tail dependence:

$$
C_{C G}^{F}(u, v ; \alpha, \delta, \theta)=\pi_{s_{t}} C_{G C}(u, v ; \delta, \theta)+\left(1-\pi_{s_{t}}\right) C_{F}(u, v ; \alpha), \quad 0 \leq \pi_{s_{t}} \leq 1,
$$

and this was the mixture estimated for the remaining Asian cases. This is very convenient, because now an increase in tail dependence (upper and lower) can be captured as just one parameter, $\pi_{s_{t}}$, goes from zero to one.

The Latin-American copulas were selected following the criteria described above. In Mexico-Argentina, the best fitting mixture was Frank, Clayton:

$$
C_{F}^{C}(u, v ; \alpha, \theta)=\pi_{s_{t}} C_{F}(u, v ; \delta)+\left(1-\pi_{s_{t}}\right) C_{F}(u, v ; \alpha), \quad 0 \leq \pi_{s_{t}} \leq 1
$$

Here, again, lower tail dependence increases as $\pi_{s_{t}}$ goes from zero to one. In MexicoBrazil the best fitting mixture was Frank, Clayton-Gumbel. Finally, in the MexicoChile case, the best fitting dependence structure was a mixture of three copulas (Clayton, Frank, Gumbel).

The mixtures are compared to the Frank (model 2) and Student (model 3) switching to find the best fitting model. As the models are nonnested, it is necessary to find a criterion to choose among them. In this paper I use the Akaike Criterion ${ }^{29}$ adjusted for small sample $\operatorname{bias}^{30}$ :

$$
A I C C=-2 \log L(\hat{\theta})+2 K+\frac{2 K(K+1)}{n-K-1},
$$

where $\log L(\hat{\theta})$ is the maximized $\log$ likelihood function, $K$ is the number of estimated parameters, and $n$ is the sample size. As the purpose of this study is to get an understanding of the structure of the data, and not prediction, the Akaike Information Criterion is preferred to other criteria that are also widely used in Economics, like the

\footnotetext{
${ }^{29}$ Breymann, Dias and Embrechts (2003) also use the Akaike criterion to select best fitting copulas.

${ }^{30}$ For a survey of model selection and inference, see Burnham and Anderson (1998).
} 
Schwartz Information Criterion. The adjustment for small sample bias is recommended when $n / K<40^{31}$. According to this criterion, the best fitting model is the one that minimizes AICC.

Detailed results are presented in Tables 4 to 19. Results for each pair of countries are presented in two tables: the first table shows estimates of parameters for the Mixture, Frank and Student switching copulas ${ }^{32}$ and tests which kind of dependence structure best describes the data at hand. Once the best fitting model has been chosen, the second table tests whether changes in dependence are statistically significant using a standard likelihood ratio test. Table 12 and Table 19 summarize all the results obtained in the above-mentioned tables for the Asian and Mexican case, respectively.

Tables 4 and 5 contain results for the Thailand-Malaysian case. Table 4 shows estimates of parameters from the Mixture, Frank and Student switching copulas. The Akaike Information Criterion (bottom of the table) selects the Mixture as the best fitting copula. This means that the increase in dependence between periods of different volatility is best described as an increase in asymmetric tail dependence. A test of the statistical significance of this change is provided in Table 5. The first column of Table 5 contains results for the Clayton and Gumbel copulas with constant parameters of the component functions and shifting weight. A weight equal to one means that the dependence structure is completely characterized by lower tail dependence (Clayton copula). Note that the weight of the Clayton copula increases, which means that more probability mass is assigned to the event of both markets crashing together when the markets are simultaneously in the high variance regime. The second column shows results for the Clayton-Gumbel mixture with constant weights. A standard likelihood-ratio test rejects the hypothesis of constant weights at the $5 \%$ level $(p$-value $=0.032)$. The first column of table 12 shows dependence parameters associated to the different $\pi^{\prime} s$. Dependence (as measured by Kendal's tau) increases in the high volatility state. Estimates are reasonable close to the empirical Kendal's tau calculated in Table 2. Lower tail dependence increases also in the high volatility state, while upper tail dependence decreases.

In the Thailand-Indonesia case (Tables 6 and 7) the best fitting copula is the Frank, Clayton-Gumbel mixture (see Table 6). The maximum likelihood estimates of

\footnotetext{
${ }^{31}$ See Burnham and Anderson (1998).
} 
the weights (first column of table 7) are in the boundaries, suggesting that a Frank copula describes the structure of dependence in tranquil periods, while the Clayton, Gumbel copula, with more probability mass in the tails, does it better in high volatility periods $^{33}$. Following Hamilton and Lin (1996), I imposed those values and reestimated the model with the purpose of calculating the standard errors of the remaining parameters. A test of constancy of weights is provided in table 7 . The third column of Table 7 presents results for the constant weight mixture. Note that the constant weight mixture estimates more parameters, and gives a lower value of the likelihood function that the switching weights mixture. Second column of table 12 shows dependence parameters associated to the different $\pi^{\prime} s$. Note again that the estimates are close to the empirical Kendall's tau shown in Table 2. Dependence and both upper and lower tail probabilities increase in the high volatility period.

In Thailand-Korea (Tables 8 and 9), the best fitting copula was a mixture of Gumbel and the independent copula. The copula originally estimated was Frank, Clayton-Gumbel, but $\theta$ attained its lower bound of zero. Also, the independent copula was obtained because the parameter of the Frank copula was not found significantly different from zero (Table 8). Note that the weight of the ClaytonGumbel copula attained its lower bound, suggesting that the series were independent in the non-crisis period. Interestingly, all copulas reflect independence in the lowvariance state. The hypothesis of constant weight is rejected (see Table 9): the constant-weight copula estimates at least the same number of parameters and gives a lower log likelihood value. This result makes the Thailand-Korea case the most dramatic in the sample, as it evolves from independence in stability to upper tail dependence in turmoil.

Results for the Thailand-Philippines case are shown in Tables 10 and 11 . Again, the best fitting copula is the Frank, Clayton-Gumbel mixture (see Table 10). The weights (first column of Table 11) move in the direction of increased tail dependence between volatility regimes. This case also provides strong evidence of switching parameters between volatility regimes. The likelihood-ratio test presented in Table 11 rejects the hypothesis of constant weights at the 5\% level (p-value = 0.0359. The second column of Table 11 shows that a mixture of the CG copula and the independent copula $(\alpha=0)$ gives the best fit in the Thailand-Philippines case.

\footnotetext{
${ }^{32}$ For clarity, only the parameters of the copula are shown.
} 
Results in Table 12 (fourth column) show dependence and both upper and lower tail probabilities increasing in the high volatility period.

Results for the Mexican crisis are shown in Tables 12 to 19. Perhaps surprisingly, in the Latin American case there was no evidence of changes in tail dependence. Although the Student copula was chosen as the best fitting model for Mexico-Argentina and Mexico-Brazil (Tables 13 and 15), the estimates of the degrees of freedom turned out to be too high (180 and 200 for Mexico-Argentina in the low and high volatility states, respectively; 44 and 49 for Mexico-Brazil). Therefore, the Normal copula was estimated in these two cases. A mixture of three copulas (independent, Clayton and Gumbel) gave the best fit for Mexico-Chile (Table 17). In the case of Mexico-Brazil, the correlation coefficient increases from 0.197 to 0.412 , and this change is significant ( $p$-value $=0.028$ ). Note that this corresponds to an increase in Kendall's tau from 0.126 to 0.270 , which is very close to the empirical results shown in Table 3. Mexico-Argentina and Mexico-Chile were the only cases in which I found evidence of a stable dependence structure across variance regimes. Mexico and Argentina appear highly interdependent even in the period of tranquillity (the correlation coefficient in the low variance state is 0.378 ), so one possible explanation for this finding is the Forbes and Rigobon (2002) argument. On the other hand, and this is relevant also for Mexico-Chile, the crisis period is short relative to the entire sample (about 10\% of the observations), and therefore the Dungey and Zhumabekova (2001) observation could also be applicable. Table 19 shows implied measures of dependence for the Latin-American case.

Finally, a note on the Student copula. In the cases in which the estimated degrees of freedom were too high, I reestimated the models imposing normality (the Normal copula). I established an upper bound of 35, and found that when the degrees of freedom attained this barrier, there was no loss of likelihood value in switching to the Normal. Interestingly, the Normal copula (tail independence) characterizes the tranquil times in all cases, with the exception of Thailand-Philippines, while the Student copula (tail dependence) turns out to be prevalent in times of turmoil.

\footnotetext{
${ }^{33}$ Interestingly, all copulas in Table 6 exhibit asymptotic tail independence in tranquil times.
} 


\section{Conclusions}

This paper provides evidence that the dependence structure between stock market returns of countries in Asia and Latin America changed during the Asian and Mexican crises. Although dependence (as measured by Kendal's tau) is low after filtering the series from state-varying volatility, changes in dependence during high variance regimes are statistically significant in most cases. In this way, most cases studied in this paper exhibit contagion in the sense of Forbes and Rigobon's (2002) definition. However, although overall dependence increases, patterns of change in tail behavior differ widely across markets, with tail dependence being more prevalent in times of financial turmoil.

This paper makes the case that structural breaks in tail dependence are a potentially important dimension of the contagion phenomenon. Changes in tail dependence should be taken into account in the design of any sound asset allocation strategy. Failing to do so can be very expensive, as recent theoretical literature has demonstrated $^{34}$. However, it is important to note that these changes are not necessarily captured by correlation shifts. If contagion is a nonlinear phenomenon, as the results in this paper suggest, it is dangerous to consider, without further investigation, the rejection of the "correlation breakdown" hypothesis as evidence of a stable dependence structure.

\footnotetext{
${ }^{34}$ See Ang and Bekaert (2002) and Das and Uppal (2003).
} 


\section{References}

Ang, A., and Bekaert, G., "International Asset Allocation with Regime Shifts,", Review of Financial Studies (15), 4, Fall 2002, 1137-1187.

Bae, K., Karolyi, G., and Stulz, R., "A New Approach to Measuring Financial Contagion", 2001, forthcoming in The Journal of Finance.

Baig, T., and Goldfajn, I., "Financial Market Contagion in the Asian Crisis", IMF Staff Papers, 46, 1999.

Bertero, E. and Mayer, Colin, "Structure and Performance: Global Interdependence of Stock Markets Around the Crash of October 1987" 307, C.E.P.R. Discussion Papers, 1989.

Boyer, B., Gibson, M., and Loretan, M., "Pitfalls in Tests for Changes in Correlation", 1999, Working Paper, Board of Governors of the Federal Reserve System.

Breymann, W., Dias, A., and Embrechts, P., "Dependence Structures for Multivariate High-Frequency Data in Finance", 2003, Quantitative Finance, 3, 1-14.

Burnham, K., and Anderson, D., "Model Selection and Inference”, 1998, Springer Verlag, New York.

Calvo, S., and Reinhart, C., "Capital Flows to Latin America: Is There Evidence of Contagion Effects?", in Calvo, Goldstein, Hochreiter (eds,) Private Capital Flows to Emerging Markets After the Mexican Crisis, (Washington, DC: Institute for International Economics, 1996).

Chesney, F., and Jondeau, E., "Does Correlation Between Stock Returns Really Increase During Turbulent Period?”, Banque de France, 2000, Working Paper.

Das, S., and Upal, R., "Systematic Risk and International Portfolio Choice”, Working Paper, 2003.

Diebold, F., Schuermann, T., and Stroughair, J., "Pitfalls and Opportunities in the Use of Extreme Value Theory in Risk Management", Journal of Risk Management, 1, 2000, 30-36.

Dungey, M., and Zhumabekova, D., "Testing for Contagion Using Correlations: Some Words of Caution", 2001, Federal Reserve Bank of San Francisco, Pacific Basin Working Paper PB01-09.

Durrleman, V., Nikeghbali, A., and Roncalli, T., "Which copula is the right one?", 2000, Groupe de Recherche Operationelle, Credit Lyonnais, France.

Forbes, K., and Rigobon, R., "No Contagion, Only Interdependence: Measuring Stock Markets Comovements", Journal of Finance, Volume 57, Number 5, October, 2002, pp 2223-2261. 
Hamilton, D. and Lin, G., "Stock Market Volatility and the Business Cycle:, Journal of Applied Econometrics, 11, 1996, 573-593.

Hamilton, D., and Susmel, R., "Autoregressive Conditional Heteroskedasticity and Changes in Regime", Journal of Econometrics, 64, 1994, 307-333.

Hartman, P., Straetmans, S. and de Vries, C., "Asset market linkages in crisis periods", Erasmus Working Paper, 2000.

Joe, H. "Multivariate Models and Dependence Concepts", 1997, Chapman and Hall.

King, M., and Wadhwani, S., "'Transmission of Volatility Between Stock Markets", 1990, Review of Financial Studies.

Klugman, S., and Parsa, R., "Fitting Bivariate Loss Distributions with Copulas", !999, Insurance, Mathematics \& Economics, 24, 139-48.

Lamoreux, C. and Lastrapes, W., "Persistence in Variance, Structural Change and the GARCH model", 1990, Journal of Business Economics and Statistics.

Longin, F., and Solnik, B., "Is the Correlation in International Equity Returns Constant: 1960-1990?", 1995, Journal of International Money and Finance, 14, 3-26. , "Extreme Correlations of International Equity Markets", 2001, The Journal of Finance, 56, 649-676.

Loretan, M., and English, W., "Evaluating "Correlation Breakdowns" During Periods of Market Volatility", 2000, Working Paper, Board of Governors of the Federal Reserve System.

Nelsen, R., “An Introduction to Copulas”, 1999, Springer-Verlag, New York.

Patton, A., "Modelling Time-Varying Exchange Rate Dependence Using the Conditional Copula", 2001a, Working Paper, University of California, San Diego.

Patton, A., "Estimation of Copula Models for Time Series of Possible Different Lengths", 2001b, Working Paper, University of California, San Diego.

Poon, S., Rockinger, M., and Tawn, J., "Modelling Extreme Value Dependence in International Stock Markets", Working Paper, 2002.

Ramchand, L., and Susmel, R., "Volatility and Cross Correlation Across Major Stock Markets", Journal of Empirical Finance, 5, 1998.

Tesar, L., and Warner, I., "Home Bias and the Globalization of Securities", 1992, NBER Working Paper. 
Table 1a: Descriptive Statistics. Asian Markets

\begin{tabular}{|c|c|c|c|c|c|}
\hline & Thailand & Malaysia & Indonesia & Korea & Philippines \\
\hline Mean & -0.296 & -0.183 & -0.267 & -0.224 & -0.116 \\
\hline Std. Dev. & 2.968 & 2.631 & 4.382 & 3.514 & 1.998 \\
\hline Skewness & 0.673 & 1.064 & -1.305 & 0.644 & 0.116 \\
\hline Kurtosis & 8.87 & 17.29 & 19.73 & 15.991 & 9.70 \\
\hline Jarque-Bera* & 973.6 & 5616.8 & 7723.1 & 4588.5 & 1207.0 \\
\hline
\end{tabular}

Table 1b: Descriptive Statistics. Latin-American Markets

\begin{tabular}{c|cccc}
\hline & Mexico & Argentina & Brazil & Chile \\
\hline Mean & -0.057 & 0.031 & 0.137 & 0.107 \\
Std. Dev. & 2.613 & 2.012 & 3.672 & 2.476 \\
Skewness & -1.022 & -0.002 & -0.036 & 0.317 \\
Kurtosis & 15.952 & 5.531 & 6.468 & 8.680 \\
Jarque-Bera* & 5553.0 & 205.8 & 387.2 & 1053.4 \\
\hline
\end{tabular}


Table 2: Univariate Results, SWARCH $(2,1)$ Model. Asian Markets

\begin{tabular}{|c|c|c|c|c|c|}
\hline & Thailand & Malaysia & Indonesia & Korea & Philippines \\
\hline $\mathrm{P}_{11}$ & $\begin{array}{l}0.997 * \\
(0.003)\end{array}$ & $\begin{array}{l}0.998^{*} \\
(0.002)\end{array}$ & $\begin{array}{l}0.998^{*} \\
(0.002)\end{array}$ & $\begin{array}{l}0.998^{*} \\
(0.002)\end{array}$ & $\begin{array}{l}0.992 * \\
(0.006)\end{array}$ \\
\hline $\mathrm{P}_{22}$ & $\begin{array}{c}1.000 \\
\text { (See text) }\end{array}$ & $\begin{array}{c}1.000 \\
\text { (See text) }\end{array}$ & $\begin{array}{c}1.000 \\
\text { (See text) }\end{array}$ & $\begin{array}{l}0.994 * \\
(0.006)\end{array}$ & $\begin{array}{l}0.992 * \\
(0.007)\end{array}$ \\
\hline g & $\begin{array}{l}7.278^{*} \\
(1.207)\end{array}$ & $\begin{array}{c}23.743 * \\
(3.868)\end{array}$ & $\begin{array}{l}26.871 * \\
(5.237)\end{array}$ & $\begin{array}{l}15.498^{*} \\
(1.003)\end{array}$ & $\begin{array}{l}9.965^{*} \\
(1.279)\end{array}$ \\
\hline $\mathrm{a} 0$ & $\begin{array}{l}1.898^{*} \\
(0.281)\end{array}$ & $\begin{array}{l}0.653^{*} \\
(0.091)\end{array}$ & $\begin{array}{l}1.018^{*} \\
(0.181)\end{array}$ & $\begin{array}{l}2.037 * \\
(0.193)\end{array}$ & $\begin{array}{l}0.560^{*} \\
(0.082)\end{array}$ \\
\hline a1 & $\begin{array}{l}0.212 * \\
(0.082)\end{array}$ & $\begin{array}{l}0.160^{*} \\
(0.067)\end{array}$ & $\begin{array}{l}0.421^{*} \\
(0.114)\end{array}$ & $\begin{array}{c}0.053 \\
(0.053)\end{array}$ & $\begin{array}{c}0.284^{*} \\
(0.02)\end{array}$ \\
\hline $\mathrm{v}$ & $\begin{array}{l}4.321 * \\
(0.797)\end{array}$ & $\begin{array}{l}4.021^{*} \\
(0.715)\end{array}$ & $\begin{array}{l}3.612 * \\
(0.566)\end{array}$ & $\begin{array}{l}5.542 * \\
(1.008)\end{array}$ & $\begin{array}{l}4.447 * \\
(0.887)\end{array}$ \\
\hline $\mathrm{mu}$ & $\begin{array}{c}-0.233^{*} \\
(0.064)\end{array}$ & $\begin{array}{c}0.001 \\
(0.035)\end{array}$ & $\begin{array}{c}0.041 \\
(0.043)\end{array}$ & $\begin{array}{l}-0.1095 \\
(0.062)\end{array}$ & $\begin{array}{c}0.007 \\
(0.037)\end{array}$ \\
\hline phi & $\begin{array}{l}0.172 * \\
(0.042)\end{array}$ & $\begin{array}{l}0.185^{*} \\
(0.042)\end{array}$ & $\begin{array}{l}0.227 * \\
(0.041)\end{array}$ & $\begin{array}{l}0.166^{*} \\
(0.039)\end{array}$ & $\begin{array}{l}0.283^{*} \\
(0.043)\end{array}$ \\
\hline $\begin{array}{l}\text { Kendall's tau } \\
\text { (low) } \\
\text { Kendall's tau } \\
\text { (high) }\end{array}$ & & $\begin{array}{l}0.162 \\
0.242 \\
\end{array}$ & $\begin{array}{l}0.130 \\
0.222 \\
\end{array}$ & $\begin{array}{l}0.023 \\
0.130 \\
\end{array}$ & $\begin{array}{l}0.119 \\
0.217 \\
\end{array}$ \\
\hline $\mathrm{LF}$ & -1444.1 & -1159.8 & -1348.7 & -1403.0 & -1117.1 \\
\hline $\begin{array}{c}\mathrm{LF}^{*} \\
\text { p-value }\end{array}$ & $\begin{array}{c}-1492.3 \\
0.00\end{array}$ & $\begin{array}{c}-1268.8 \\
0.00\end{array}$ & $\begin{array}{c}-1434.8 \\
0.00\end{array}$ & $\begin{array}{c}-1466.6 \\
0.00\end{array}$ & $\begin{array}{c}-1163.0 \\
0.00\end{array}$ \\
\hline
\end{tabular}

* Significant at the $5 \%$ level.

Kendal's tau (low/high) is the empirical Kendal's tau between Thailand and the corresponding country calculated from the residuals of the low/high variance state.

$\mathrm{LF}=$ Maximum Value of the Likelihood Function

$\mathrm{LF}^{*}=$ Maximum Value of the restricted Likelihood Function (no regime switching)

p-value $=$ probability value of a standard LR test (null = no regime switching) 
Table 3: Univariate Results, SWARCH $(2,1)$ Model. Latin-American Markets

\begin{tabular}{|c|c|c|c|c|}
\hline & Mexico & Argentina & Brazil & Chile \\
\hline $\mathrm{P}_{11}$ & $\begin{array}{l}0.997 * \\
(0.004)\end{array}$ & $\begin{array}{l}0.995^{*} \\
(0.004)\end{array}$ & $\begin{array}{l}0.988^{*} \\
(0.009)\end{array}$ & $\begin{array}{l}0.969 * \\
(0.019)\end{array}$ \\
\hline $\mathrm{P}_{22}$ & $\begin{array}{l}0.978 * \\
(0.025)\end{array}$ & $\begin{array}{l}0.986^{*} \\
(0.009)\end{array}$ & $\begin{array}{l}0.979 * \\
(0.013)\end{array}$ & $\begin{array}{l}0.980 * \\
(0.013)\end{array}$ \\
\hline g & $\begin{array}{l}15.188 * \\
(5.057)\end{array}$ & $\begin{array}{l}3.823 * \\
(0.557)\end{array}$ & $\begin{array}{l}3.496^{*} \\
(0.497)\end{array}$ & $\begin{array}{c}3.400^{*} \\
0.614\end{array}$ \\
\hline $\mathrm{a} 0$ & $\begin{array}{l}1.896^{*} \\
(0.203)\end{array}$ & $\begin{array}{l}2.109^{*} \\
(0.194)\end{array}$ & $\begin{array}{l}6.251^{*} \\
(0.655)\end{array}$ & $\begin{array}{l}0.485^{*} \\
(0.091)\end{array}$ \\
\hline a1 & $\begin{array}{l}0.210 * \\
(0.105)\end{array}$ & $\begin{array}{c}0.068 \\
(0.049)\end{array}$ & $\begin{array}{c}0.050 \\
(0.051)\end{array}$ & $\begin{array}{l}0.218^{*} \\
(0.061)\end{array}$ \\
\hline $\mathrm{v}$ & $\begin{array}{l}5.552 * \\
(1.097)\end{array}$ & $\begin{array}{c}17.696 \\
(1.000)\end{array}$ & $\begin{array}{l}11.592 * \\
(1.010)\end{array}$ & $\begin{array}{l}8.303^{*} \\
(2.700)\end{array}$ \\
\hline $\mathrm{mu}$ & $\begin{array}{c}0.021 \\
(0.052)\end{array}$ & $\begin{array}{c}0.073 \\
(0.061)\end{array}$ & $\begin{array}{c}0.184 \\
(0.111)\end{array}$ & $\begin{array}{l}0.083 * \\
(0.037)\end{array}$ \\
\hline phi & $\begin{array}{l}0.218^{*} \\
(0.042)\end{array}$ & $\begin{array}{l}0.105 * \\
(0.039)\end{array}$ & $\begin{array}{c}0.071 \\
(0.038)\end{array}$ & $\begin{array}{l}0.172 * \\
(0.040)\end{array}$ \\
\hline Kendall's tau (low) & & 0.238 & 0.120 & 0.134 \\
\hline Kendall's tau (high) & & 0.372 & 0.268 & 0.297 \\
\hline $\mathrm{LF}$ & -1524.4 & -1572.7 & -2053.1 & -1213.5 \\
\hline $\mathrm{LF}^{*}$ & -1555.0 & -1598.1 & -2073.0 & -1223.1 \\
\hline p-vlue & $2.26 \times 10^{-23}$ & $5.24 \times 10^{-11}$ & $21.17 \times 10^{-08}$ & $2.49 \times 10^{-04}$ \\
\hline
\end{tabular}

* Significant at the $5 \%$ level.

Kendal's tau (low/high) is the empirical Kendal's tau between Mexico and the corresponding country calculated from the residuals of the low/high variance state.

$\mathrm{LF}=$ Maximum Value of the Likelihood Function

$\mathrm{LF}^{*}=$ Maximum Value of the restricted Likelihood Function (no regime switching)

$\mathrm{p}$-value $=$ probability value of a standard LR test (null $=$ no regime switching) 


\section{Table 4: Bivariate Results. Thailand-Malaysia. Estimation of Copula Models}

The first column gives estimates for the Mixture (Clayton, Gumbel). $\pi_{\mathrm{L}}$ is the weight of the Clayton copula in the low volatility state, $\pi_{\mathrm{H}}$ is the weight of the Clayton copula in the high volatility state. Lower tail dependence increases with $\pi . \theta$ and $\delta$ are the parameters of the Clayton and Gumbel copulas, respectively. The second column gives estimates for the Frank Switching model. $\alpha_{\mathrm{L}}$ is the parameter of the Frank copula in the low variance state. $\alpha_{\mathrm{H}}$ is the parameter of the Frank copula in the high variance state. Dependence increases with $\alpha$. The third column gives estimates for the switching Student $t$ copula. $\rho_{\mathrm{L}}$ and $\rho_{\mathrm{H}}$, and $v_{\mathrm{L}}$ and $v_{\mathrm{H}}$ are the correlation coefficients and the degrees of freedom in the low and high variance states respectively. Standard errors are on the right of each column. Only the copula parameters are shown.

\begin{tabular}{|c|c|c|c|c|c|c|}
\hline & $\begin{array}{c}\text { Mixture } \\
\text { Switching }\end{array}$ & Std Error & $\begin{array}{c}\text { Frank } \\
\text { Switching }\end{array}$ & Std Error & $\begin{array}{c}\text { Student } \mathrm{t} \\
\text { Switching }\end{array}$ & $\begin{array}{c}\text { Standard } \\
\text { Errors }\end{array}$ \\
\hline$\pi_{L}$ & 0.091 & 0.057 & & & & \\
\hline$\pi_{H}$ & 0.277 & $0.079 *$ & & & & \\
\hline$\theta$ & 3.860 & $1.072 *$ & & & & \\
\hline$\delta$ & 1.152 & $0.046^{*}$ & & & & \\
\hline$\alpha_{L}$ & & & 1.673 & $0.030^{*}$ & & \\
\hline$\alpha_{H}$ & & & 2.709 & $0.509 *$ & & \\
\hline$\rho_{L}$ & & & & & 0.275 & $0.025^{*}$ \\
\hline$\rho_{H}$ & & & & & 0.412 & $0.098^{*}$ \\
\hline$v_{L}$ & & & & & $>35^{* *}$ & \\
\hline$v_{H}$ & & & & & 3.350 & $1.392 *$ \\
\hline $\begin{array}{c}\text { LF } \\
\text { Number of }\end{array}$ & -2552.7 & & -2567.3 & & -2559.6 & \\
\hline $\begin{array}{c}\text { Param } \\
\text { AICC }\end{array}$ & $\begin{array}{c}21 \\
5148.9\end{array}$ & & $\begin{array}{c}19 \\
5173.8\end{array}$ & & $\begin{array}{c}20 \\
5160.5\end{array}$ & \\
\hline
\end{tabular}

* Significant at the $5 \%$ level.

LF is the maximized log likelihood function

Number of Param. is the number of estimated parameters.

AICC is the Akaike Information criterion adjunted for small sample bias $=$

$-2 \mathrm{LF}+2 \mathrm{~K}+2 \mathrm{~K}(\mathrm{~K}+1) /(\mathrm{n}-\mathrm{K}-1)$, where $\mathrm{K}=$ Number of Param, and $\mathrm{n}$ is the sample size.

** Degrees of freedom higher than 35. Normal copula was estimated for that state. 


\section{Table 5: Bivariate Results. Thailand-Malaysia}

The first column gives estimates for the Mixture (Clayton, Gumbel). $\pi_{\mathrm{L}}$ is the weight of the Clayton copula in the low volatility state, $\pi_{\mathrm{H}}$ is the weight of the Clayton copula in the high volatility state. Lower tail dependence increases with $\pi . \theta$ and $\delta$ are the parameters of the Clayton and Gumbel copulas, respectively. The second column gives estimates for the constant weight mixture. Standard errors are on the right of each column.

\begin{tabular}{|c|c|c|c|c|}
\hline & Mixture Switching & Std Error & Mixture Constant & Std Error \\
\hline$\pi_{L}$ & 0.091 & 0.057 & & \\
\hline$\pi_{H}$ & 0.277 & $0.079 *$ & 0.141 & $0.053 *$ \\
\hline$\theta$ & 3.860 & $1.072 *$ & 6.710 & $3.293 *$ \\
\hline$\delta$ & 1.152 & $0.046 *$ & 1.165 & $0.044^{*}$ \\
\hline g_M & 20.630 & $3.050 *$ & 19.341 & $2.337^{*}$ \\
\hline $\mathrm{a} 0 \mathrm{M}$ & 0.680 & $0.110^{*}$ & 0.693 & $0.091 *$ \\
\hline a1_M & 0.168 & $0.062 *$ & 0.165 & $0.050 *$ \\
\hline $\mathrm{v} M$ & 3.878 & $0.734 *$ & 4.012 & $0.565^{*}$ \\
\hline Mü M & 0.005 & 0.037 & -0.008 & 0.034 \\
\hline phi_M & 0.143 & $0.041 *$ & 0.123 & $0.036 *$ \\
\hline g_T & 9.757 & $1.781 *$ & 9.367 & $1.105^{*}$ \\
\hline $\mathrm{a} 0 \mathrm{~T}$ & 1.339 & $0.230 *$ & 1.337 & $0.162^{*}$ \\
\hline a1 $\mathrm{T}$ & 0.115 & $0.052 *$ & 0.111 & $0.047^{*}$ \\
\hline $\mathrm{v}_{-}^{-} \mathrm{T}$ & 5.852 & $1.372 *$ & 5.723 & $1.082 *$ \\
\hline $\mathrm{Mu}$ - T & -0.180 & $0.091^{*}$ & -0.166 & $0.060 *$ \\
\hline Phi_T & 0.167 & $0.043 *$ & 0.168 & $0.030 *$ \\
\hline $\begin{array}{c}\text { LF } \\
\text { p-value }\end{array}$ & $\begin{array}{c}-2552.7 \\
0.032\end{array}$ & & -2555.0 & \\
\hline $\begin{array}{c}\text { Number of } \\
\text { Param }\end{array}$ & 21 & & 20 & \\
\hline
\end{tabular}

* Significant at the 5\% level.

LF is the maximized likelihood function p-value LR test (1 degree of freedom).

Number of Param. is the number of estimated parameters. 


\section{Table 6: Bivariate Results. Thailand-Indonesia. Estimation of Copula Models}

The first column gives estimates for the Mixture (Frank, Clayton-Gumbel). $\pi_{\mathrm{L}}$ is the weight of the Clayton copula in the low volatility state, $\pi_{\mathrm{H}}$ is the weight of the Clayton copula in the high volatility state. Lower tail dependence increases with $\pi . \theta$ and $\delta$ are the parameters of the Clayton and Gumbel copulas, respectively. The second column gives estimates for the Frank Switching model. $\alpha_{\mathrm{L}}$ is the parameter of the Frank copula in the low variance state. $\alpha_{H}$ is the parameter of the Frank copula in the high variance state. Dependence increases with $\alpha$. The third column gives estimates for the switching Student t copula. $\rho_{\mathrm{L}}$ and $\rho_{\mathrm{H}}$, and $v_{\mathrm{L}}$ and $v_{\mathrm{H}}$ are the correlation coefficients and the degrees of freedom in the low and high variance states respectively. Standard errors are on the right of each column. Only the copula parameters are shown.

\begin{tabular}{|c|c|c|c|c|c|c|}
\hline & $\begin{array}{c}\text { Mixture } \\
\text { Switching }\end{array}$ & Std Error & $\begin{array}{c}\text { Frank } \\
\text { Switching } \\
\end{array}$ & Std Error & $\begin{array}{c}\text { Student t } \\
\text { Switching }\end{array}$ & Std Error \\
\hline$\pi_{L}$ & 0.000 & See Text & & & & \\
\hline$\pi_{H}$ & 1.000 & See Text & & & & \\
\hline$\theta$ & 0.235 & $0.103 *$ & & & & \\
\hline$\delta$ & 1.158 & $0.064 *$ & & & & \\
\hline$\alpha$ & 1.201 & $0.331 *$ & & & & \\
\hline$\alpha_{L}$ & & & 1.221 & $0.389 *$ & & \\
\hline$\alpha_{H}$ & & & 2.255 & $0.231^{*}$ & & \\
\hline$\rho_{L}$ & & & & & 0.191 & $0.053 *$ \\
\hline$\rho_{H}$ & & & & & 0.354 & $0.058 *$ \\
\hline$v_{L}$ & & & & & $>35^{* *}$ & \\
\hline$v_{H}$ & & & & & 6.754 & $1.325^{*}$ \\
\hline $\begin{array}{c}\text { LF } \\
\text { Number of } \\
\text { Param } \\
\text { AICC }\end{array}$ & $\begin{array}{c}-2761.5 \\
19 \\
5562.2\end{array}$ & & $\begin{array}{c}-2765.5 \\
18 \\
5568.1\end{array}$ & & $\begin{array}{c}-2762.1 \\
19 \\
5563.4\end{array}$ & \\
\hline
\end{tabular}

* Significant at the $5 \%$ level.

LF is the maximized log likelihood function

Number of Param. is the number of estimated parameters.

AICC is the Akaike Information criterion adjunted for small sample bias =

$-2 L F+2 K+2 K(K+1) /(n-K-1)$, where $K=$ Number of Param, and $n$ is the sample size.

** Degrees of freedom higher than 35. Normal copula was estimated for that state. 


\section{Table 7: Bivariate Results. Thailand-Indonesia}

The first column gives estimates for the Mixture (Frank, Clayton-Gumbel). $\pi_{\mathrm{L}}$ is the weight of the Clayton copula in the low volatility state, $\pi_{\mathrm{H}}$ is the weight of the Clayton copula in the high volatility state. Tail dependence increases with $\pi . \theta, \delta$ and $\alpha$ are the parameters of the Clayton, Gumbel and Frank copulas, respectively. The second column gives estimates for the constant weight mixture. Standard errors are on the right of each column.

\begin{tabular}{|c|c|c|c|c|}
\hline & Mixture Switching & Std Error & Mixture Constant & Std Error \\
\hline $\begin{array}{l}\pi_{L} \\
\pi_{H}\end{array}$ & $\begin{array}{l}0.000 \\
1.000\end{array}$ & $\begin{array}{l}\text { See Text } \\
\text { See Text }\end{array}$ & 0.300 & 0.273 \\
\hline $\begin{array}{l}\theta \\
\delta \\
\alpha\end{array}$ & $\begin{array}{l}0.235 \\
1.158 \\
1.201\end{array}$ & $\begin{array}{l}0.103 * \\
0.064 * \\
0.331 *\end{array}$ & $\begin{array}{l}0.464 \\
1.425 \\
0.710\end{array}$ & $\begin{array}{c}0.535 \\
0.367^{*} \\
0.646\end{array}$ \\
\hline $\begin{array}{l}\text { g_I } \\
\text { a0_I } \\
\text { a1_I } \\
\text { v_I } \\
\text { mu_I } \\
\text { phi_I }\end{array}$ & $\begin{array}{c}25.761 \\
1.018 \\
0.408 \\
3.656 \\
0.044 \\
0.200\end{array}$ & $\begin{array}{c}1.001^{*} \\
0.168^{*} \\
0.116^{*} \\
0.611^{*} \\
0.044 \\
0.042^{*}\end{array}$ & $\begin{array}{c}24.248 \\
1.122 \\
0.437 \\
3.449 \\
0.042 \\
0.197\end{array}$ & $\begin{array}{c}4.815^{*} \\
0.206^{*} \\
0.116^{*} \\
0.516^{*} \\
0.046 \\
0.038^{*}\end{array}$ \\
\hline $\begin{array}{c}\text { g_t } \\
\text { a0_T } \\
\text { a1_T } \\
\text { v_T } \\
\text { mu_T } \\
\text { phi_T }\end{array}$ & $\begin{array}{c}7.343 \\
1.937 \\
0.163 \\
4.308 \\
-0.226 \\
0.130\end{array}$ & $\begin{array}{l}0.993^{*} \\
0.291^{*} \\
0.076^{*} \\
0.972^{*} \\
0.064^{*} \\
0.040^{*}\end{array}$ & $\begin{array}{c}7.635 \\
2.040 \\
0.118 \\
4.905 \\
-0.231 \\
0.121\end{array}$ & $\begin{array}{l}1.170^{*} \\
0.292^{*} \\
0.067^{*} \\
1.030^{*} \\
0.064^{*} \\
0.041^{*}\end{array}$ \\
\hline $\begin{array}{c}\text { LF } \\
\text { p-value } \\
\text { Number of Param }\end{array}$ & $\begin{array}{c}-2761.5 \\
- \\
19\end{array}$ & & $\begin{array}{c}-2764.2 \\
20\end{array}$ & \\
\hline
\end{tabular}

* Significant at the $5 \%$ level.

LF is the maximized likelihood function

p-value LR test (1 degree of freedom).

Number of Param. is the number of estimated parameters. 


\section{Table 8: Bivariate Results. Thailand-Korea: Estimation of Copula Models}

The first column gives estimates for the Mixture (Frank, Clayton-Gumbel). $\pi_{\mathrm{L}}$ is the weight of the Clayton copula in the low volatility state. $\pi_{\mathrm{H}}$ is the weight of the Clayton copula in the high volatility state. Lower tail dependence increases with $\pi . \theta$ and $\delta$ are the parameters of the Clayton and Gumbel copulas, respectively. $\alpha$ is the parameter of the Frank copula (assumed zero in column two). The third column gives estimates for the Frank Switching model. $\alpha_{\mathrm{L}}$ is the parameter of the Frank copula in the low variance state. $\alpha_{\mathrm{H}}$ is the parameter of the Frank copula in the high variance state. Dependence increases with $\alpha$. The fourth column gives estimates for the switching Student t copula. $\rho_{\mathrm{L}}$ and $\rho_{\mathrm{H}}$, and $v_{\mathrm{L}}$ and $v_{\mathrm{H}}$ are the correlation coefficients and the degrees of freedom in the low and high variance states respectively. Standard errors are on the right of each column. Only the copula parameters are shown.

\begin{tabular}{|c|c|c|c|c|c|c|c|c|}
\hline & $\begin{array}{c}\text { Mixture } \\
\text { Switching } \\
\end{array}$ & Std Error & $\begin{array}{c}\text { Mixture } \\
\text { Switching } \\
\alpha=0\end{array}$ & Std Error & $\begin{array}{c}\text { Frank } \\
\text { Switching } \\
\end{array}$ & Std Error & $\begin{array}{c}\text { Student t } \\
\text { Switching }\end{array}$ & $\begin{array}{c}\text { Standard } \\
\text { Errors }\end{array}$ \\
\hline$\pi_{L}$ & 0.000 & See Text & 0.000 & See Text & & & & \\
\hline$\pi_{H}$ & 0.251 & 0.174 & 0.301 & $0.126^{*}$ & & & & \\
\hline$\theta$ & 0.000 & See Text & 0.000 & See Text & & & & \\
\hline$\delta$ & 2.013 & $0.952^{*}$ & 1.888 & $0.529 *$ & & & & \\
\hline$\alpha$ & 0.242 & 0.306 & & & & & & \\
\hline$\alpha_{L}$ & & & & & 0.209 & 0.997 & & \\
\hline$\alpha_{H}$ & & & & & 1.354 & $0.402 *$ & & \\
\hline$\rho_{L}$ & & & & & & & 0.061 & 0.056 \\
\hline$\rho_{H}$ & & & & & & & 0.218 & $0.064 *$ \\
\hline$v_{L}$ & & & & & & & $>35^{* *}$ & \\
\hline$v_{H}$ & & & & & & & 6.659 & $3.176^{*}$ \\
\hline $\begin{array}{c}\text { LF } \\
\text { Number } \\
\text { of Param } \\
\text { AICC }\end{array}$ & $\begin{array}{c}-2835.4 \\
19 \\
5710.0\end{array}$ & & $\begin{array}{c}-2835.7 \\
18 \\
5708.5\end{array}$ & & $\begin{array}{c}-2838.8 \\
18 \\
5714.7\end{array}$ & & $\begin{array}{c}-2836.5 \\
19 \\
5712.2\end{array}$ & \\
\hline
\end{tabular}

* Significant at the 5\% level.

LF is the maximized log likelihood function

Number of Param. is the number of estimated parameters.

AICC is the Akaike Information criterion adjunted for small sample bias =

$-2 \mathrm{LF}+2 \mathrm{~K}+2 \mathrm{~K}(\mathrm{~K}+1) /(\mathrm{n}-\mathrm{K}-1)$, where $\mathrm{K}=$ Number of Param, and $\mathrm{n}$ is the sample size.

** Degrees of freedom higher than 35 . Normal copula was estimated for that state. 


\section{Table 9: Bivariate Results. Thailand-Korea}

The first column gives estimates for the Mixture (Frank, Clayton-Gumbel). $\pi_{\mathrm{L}}$ is the weight of the Clayton copula in the low volatility state, $\pi_{\mathrm{H}}$ is the weight of the Clayton copula in the high volatility state. Tail dependence increases with $\pi . \theta, \delta$ and $\alpha$ are the parameters of the Clayton, Gumbel and Frank copulas, respectively. The second column gives estimates for the constant weight mixture. Standard errors are on the right of each column.

\begin{tabular}{|c|c|c|c|c|}
\hline & $\begin{array}{c}\text { Mixture Switching } \\
\qquad \alpha=0\end{array}$ & Std Error & Mixture Constant & Std Error \\
\hline$\pi_{L}$ & 0.000 & See Text & & \\
\hline$\pi_{H}$ & 0.301 & $0.126 *$ & 0.252 & 0.174 \\
\hline$\theta$ & 0.000 & See Text & 0.000 & See Text \\
\hline$\delta$ & 1.888 & $0.529 *$ & 2.013 & $0.952 *$ \\
\hline$\alpha$ & & & 0.242 & 0.306 \\
\hline g_I & 13.828 & $2.198^{*}$ & 13.857 & $2.253^{*}$ \\
\hline a0_I & 2.010 & $0.216^{*}$ & 2.005 & $0.186^{*}$ \\
\hline a1_I & 0.069 & 0.055 & 0.069 & 0.052 \\
\hline v_I & 5.718 & $1.237^{*}$ & 5.740 & $1.382 *$ \\
\hline mu_I & -0.113 & 0.062 & -0.117 & 0.063 \\
\hline phi_I & 0.153 & $0.038 *$ & 0.154 & $0.038 *$ \\
\hline g_T & 8.159 & $1.242 *$ & 8.176 & $1.254^{*}$ \\
\hline $\mathrm{a} 0 \_\mathrm{T}$ & 1.849 & $0.236^{*}$ & 1.845 & $0.241 *$ \\
\hline al_- T & 0.208 & $0.026^{*}$ & 0.210 & $0.081 *$ \\
\hline$v_{-} \bar{T}$ & 4.587 & $0.828^{*}$ & 4.594 & $0.936^{*}$ \\
\hline mu_T & -0.233 & $0.063^{*}$ & -0.234 & $0.065^{*}$ \\
\hline phi_T & 0.163 & $0.043^{*}$ & 0.162 & $0.041 *$ \\
\hline $\begin{array}{c}\text { LF } \\
\text { p-value }\end{array}$ & -2835.7 & & -2839.4 & \\
\hline Number of Param & 19 & & 20 & \\
\hline
\end{tabular}

* Significant at the $5 \%$ level.

LF is the maximized likelihood function p-value LR test (1 degree of freedom).

Number of Param. is the number of estimated parameters. 


\section{Table 10: Bivariate Results. Thailand-Philippines. Estimation of Copula Models}

The first column gives estimates for the Mixture (Frank, Clayton-Gumbel). $\pi_{\mathrm{L}}$ is the weight of the Clayton copula in the low volatility state, $\pi_{\mathrm{H}}$ is the weight of the Clayton copula in the high volatility state. Lower tail dependence increases with $\pi . \theta$ and $\delta$ are the parameters of the Clayton and Gumbel copulas, respectively. The second column gives estimates for the Frank Switching model. $\alpha_{\mathrm{L}}$ is the parameter of the Frank copula in the low variance state. $\alpha_{H}$ is the parameter of the Frank copula in the high variance state. Dependence increases with $\alpha$. The third column gives estimates for the switching Student $t$ copula. $\rho_{\mathrm{L}}$ and $\rho_{\mathrm{H}}$, and $v_{\mathrm{L}}$ and $v_{\mathrm{H}}$ are the correlation coefficients and the degrees of freedom in the low and high variance states respectively. Standard errors are on the right of each column. Only the copula parameters are shown.

\begin{tabular}{|c|c|c|c|c|c|c|c|c|}
\hline & $\begin{array}{c}\text { Mixture } \\
\text { Switching }\end{array}$ & Std Error & \begin{tabular}{|c|} 
Mixture \\
Switching \\
$\alpha=0$ \\
\end{tabular} & Std Error & $\begin{array}{c}\text { Frank } \\
\text { Switching }\end{array}$ & Std Error & $\begin{array}{l}\text { Student t } \\
\text { Switching }\end{array}$ & Std Error \\
\hline$\pi_{L}$ & 0.175 & 0.166 & 0.245 & $0.090^{*}$ & & & & \\
\hline$\pi_{H}$ & 0.401 & $0.172 *$ & 0.463 & $0.102 *$ & & & & \\
\hline$\theta$ & 1.005 & 0.662 & 0.913 & $0.416^{*}$ & & & & \\
\hline$\delta$ & 1.460 & $0.301^{*}$ & 1.400 & $0.220^{*}$ & & & & \\
\hline$\alpha$ & 0.399 & 0.837 & & & & & & \\
\hline$\alpha_{L}$ & & & & & $1.186^{*}$ & 0.348 & & \\
\hline$\alpha_{H}$ & & & & & $2.312^{*}$ & 0.397 & & \\
\hline$\rho_{L}$ & & & & & & & 0.195 & $0.058 *$ \\
\hline$\rho_{H}$ & & & & & & & 0.349 & $0.063 *$ \\
\hline$v_{L}$ & & & & & & & $>35^{* *}$ & \\
\hline$v_{H}$ & & & & & & & 3.763 & $1.409 *$ \\
\hline $\begin{array}{c}\text { LF } \\
\text { Number } \\
\text { of Param } \\
\text { AICC }\end{array}$ & $\begin{array}{c}-2519.7 \\
\\
22 \\
5085.0\end{array}$ & & $\begin{array}{c}-2520.0 \\
\\
21 \\
5083.5\end{array}$ & & $\begin{array}{c}-2530.3 \\
19 \\
5099.8\end{array}$ & & $\begin{array}{c}-2522.2 \\
\\
20 \\
5085.7\end{array}$ & \\
\hline
\end{tabular}

* Significant at the $5 \%$ level.

LF is the maximized log likelihood function

Number of Param. is the number of estimated parameters.

AICC is the Akaike Information criterion adjunted for small sample bias =

$-2 \mathrm{LF}+2 \mathrm{~K}+2 \mathrm{~K}(\mathrm{~K}+1) /(\mathrm{n}-\mathrm{K}-1)$, where $\mathrm{K}=$ Number of Param, and $\mathrm{n}$ is the sample size.

** Degrees of freedom higher than 35 . Normal copula was estimated for that state. 


\section{Table 11: Bivariate Results. Thailand-Philippines}

The first and second columns give estimates for the Mixture (Frank, Clayton-Gumbel). $\pi_{\mathrm{L}}$ is the weight of the Clayton copula in the low volatility state, $\pi_{\mathrm{H}}$ is the weight of the Clayton copula in the high volatility state. Tail dependence increases with $\pi . \theta, \delta$ and $\alpha$ are the parameters of the Clayton, Gumbel and Frank copulas, respectively. The third column gives estimates for the constant weight mixture. Standard errors are on the right of each column.

\begin{tabular}{|c|c|c|c|c|c|c|}
\hline & $\begin{array}{c}\text { Mixture } \\
\text { Switching }\end{array}$ & Std Error & $\begin{array}{c}\text { Mixture } \\
\text { Switching } \\
\alpha=0\end{array}$ & Std Error & $\begin{array}{l}\text { Mixture } \\
\text { Constant }\end{array}$ & Std Erro1 \\
\hline$\pi_{L}$ & $\begin{array}{c}0.175 \\
0.401 *\end{array}$ & $\begin{array}{l}0.166 \\
0.172\end{array}$ & $\begin{array}{l}0.245^{*} \\
0.463 *\end{array}$ & $\begin{array}{l}0.090 \\
0.102\end{array}$ & $0.378^{*}$ & 0.085 \\
\hline$\theta$ & $1.005 *$ & 0.662 & $0.913 *$ & 0.416 & $0.924 *$ & 0.397 \\
\hline$\delta$ & $1.460 *$ & 0.301 & $1.400 *$ & 0.220 & $1.327 *$ & 0.192 \\
\hline$\alpha$ & 0.399 & $\mathbf{0 . 8 3 7}$ & & & & \\
\hline G_Ph & $10.870^{*}$ & 1.000 & $10.834 *$ & 1.034 & $10.284^{*}$ & 1.019 \\
\hline $\mathrm{a} 0 \_\mathrm{Ph}$ & $0.613 *$ & 0.081 & $0.615^{*}$ & 0.081 & $0.628^{*}$ & 0.085 \\
\hline $\begin{array}{l}\text { a1_Ph } \\
\text { V_Ph }\end{array}$ & $\begin{array}{l}0.234^{*} \\
4.656^{*}\end{array}$ & $\begin{array}{l}0.075 \\
0.992\end{array}$ & $\begin{array}{l}0.236^{*} \\
4.574^{*}\end{array}$ & $\begin{array}{l}0.077 \\
0.969\end{array}$ & $\begin{array}{l}0.240^{*} \\
4.555^{*}\end{array}$ & $\begin{array}{l}0.080 \\
0.991\end{array}$ \\
\hline $\begin{array}{l}\text { mu_Ph } \\
\text { phi_Ph }\end{array}$ & $\begin{array}{l}-0.002 \\
0.253^{*}\end{array}$ & $\begin{array}{l}0.036 \\
0.038\end{array}$ & $\begin{array}{l}-0.001 \\
0.255^{*}\end{array}$ & $\begin{array}{l}0.037 \\
0.039\end{array}$ & $\begin{array}{l}-0.004 \\
0.255^{*}\end{array}$ & $\begin{array}{l}0.036 \\
0.039\end{array}$ \\
\hline $\mathrm{G}_{-} \mathrm{T}$ & $7.052 *$ & 0.991 & $6.989 *$ & 0.994 & $6.581 *$ & 0.978 \\
\hline a0_T & $1.855^{*}$ & 0.261 & $1.884^{*}$ & 0.266 & $1.940 *$ & 0.269 \\
\hline a1_T & $0.170 *$ & 0.071 & $0.169^{*}$ & 0.070 & $0.174 *$ & 0.063 \\
\hline $\mathrm{V}_{-} \mathrm{T}$ & $4.540 *$ & 0.984 & $4.480 *$ & 0.910 & $4.494 *$ & 0.811 \\
\hline $\mathrm{mu} \mathrm{T}$ & $-0.228^{*}$ & 0.064 & $-0.228^{*}$ & 0.064 & $-0.237^{*}$ & 0.047 \\
\hline phi_T & $0.129 *$ & 0.040 & $0.133^{*}$ & 0.040 & $0.137^{*}$ & 0.040 \\
\hline $\begin{array}{c}\text { LF } \\
\text { p-value }\end{array}$ & -2519.7 & & $\begin{array}{c}-2520.0 \\
0.0359\end{array}$ & & -2522.2 & \\
\hline $\begin{array}{c}\text { Number of } \\
\text { Param }\end{array}$ & 21 & & 20 & & 19 & \\
\hline
\end{tabular}

* Significant at the 5\% level.

LF is the maximized likelihood function p-value LR test (1 degree of freedom).

Number of Param. is the number of estimated parameters. 
Table 12: Summary of Results: Asian Case (generator: Thailand)

\begin{tabular}{lcccc}
\hline & $\begin{array}{c}\text { Malaysia } \\
(\mathrm{Cla}, \mathrm{Gu})\end{array}$ & $\begin{array}{c}\text { Indonesia } \\
(\text { Fra,Cla-Gu })\end{array}$ & $\begin{array}{c}\text { Korea } \\
(\mathrm{Fra}, \mathrm{Gu})\end{array}$ & $\begin{array}{c}\text { Philippines } \\
(\text { Fra,Cla-Gu })\end{array}$ \\
\hline $\begin{array}{l}\text { TDependence } \\
\uparrow \text { Tail Dependence }\end{array}$ & $\begin{array}{c}\text { Yes } \\
\text { Yes }\end{array}$ & $\begin{array}{c}\text { Yes } \\
\text { Yes }\end{array}$ & $\begin{array}{c}\text { Yes } \\
\text { Yes }\end{array}$ & $\begin{array}{c}\text { Yes } \\
\text { Yes }\end{array}$ \\
\hline$\tau_{L}$ (Empirical) & 0.162 & 0.130 & 0.023 & 0.119 \\
$\tau_{H}$ (Empirical) & 0.242 & 0.222 & 0.130 & 0.217 \\
$\tau_{L}$ (Estimated) & 0.178 & 0.132 & 0.000 & 0.125 \\
$\tau_{H}$ (Estimated) & 0.269 & 0.228 & 0.146 & 0.236 \\
\hline & & & & 0.148 \\
$\lambda_{L}$ (Low Variance) & 0.078 & 0.000 & 0.00 & 0.280 \\
$\lambda_{L}$ (HighVariance) & 0.224 & 0.078 & 0.00 & 0.091 \\
$\lambda_{U}$ (Low Variance) & 0.155 & 0.000 & 0.000 & 0.171 \\
$\lambda_{U}$ (HighVariance) & 0.125 & 0.180 & 0.167 & \\
\hline
\end{tabular}

$\tau_{\mathrm{i}}$ is Kendall's tau in state $\mathrm{i}(\mathrm{i}=$ Low, High)

$\lambda \mathrm{j}$ is the tail probability in the Low/High variance state $(\mathrm{j}=$ Lower, Upper $)$ 


\section{Table 13: Bivariate Results. Mexico-Argentina. Estimation of Copula Models}

The first column gives estimates for the Mixture (Frank, Clayton). $\pi_{\mathrm{L}}$ is the weight of the Clayton copula in the low volatility state, $\pi_{\mathrm{H}}$ is the weight of the Clayton copula in the high volatility state. Lower tail dependence increases with $\pi . \theta$ and $\delta$ are the parameters of the Clayton and Gumbel copulas, respectively. The second column gives estimates for the Frank Switching model. $\alpha_{\mathrm{L}}$ is the parameter of the Frank copula in the low variance state. $\alpha_{\mathrm{H}}$ is the parameter of the Frank copula in the high variance state. Dependence increases with $\alpha$. The third column gives estimates for the switching Student $t$ copula. $\rho_{\mathrm{L}}$ and $\rho_{\mathrm{H}}$, and $v_{\mathrm{L}}$ and $v_{\mathrm{H}}$ are the correlation coefficients and the degrees of freedom in the low and high variance states respectively. Standard errors are on the right of each column. Only the copula parameters are shown.

\begin{tabular}{|c|c|c|c|c|c|c|}
\hline & $\begin{array}{c}\text { Mixture } \\
\text { Switching }\end{array}$ & Std Error & $\begin{array}{c}\text { Frank } \\
\text { Switching }\end{array}$ & Std Error & $\begin{array}{c}\text { Student t } \\
\text { Switching }\end{array}$ & Std Error \\
\hline$\pi_{L}$ & 0.050 & 0.049 & \multirow{10}{*}{$\begin{array}{l}2.330 \\
3.901\end{array}$} & \multirow{10}{*}{$\begin{array}{l}0.251^{*} \\
0.996^{*}\end{array}$} & & \multirow{10}{*}{$\begin{array}{l}0.035^{*} \\
0.078^{*}\end{array}$} \\
\hline$\pi_{H}$ & 0.354 & $0.183^{*}$ & & & & \\
\hline$\theta$ & 2.355 & $0.980^{*}$ & & & & \\
\hline$\alpha$ & 2.213 & $0.296^{*}$ & & & & \\
\hline$\alpha_{L}$ & & & & & & \\
\hline$\alpha_{H}$ & & & & & & \\
\hline$\rho_{L}$ & & & & & 0.378 & \\
\hline$\rho_{H}$ & & & & & 0.495 & \\
\hline$v_{L}$ & & & & & $>35^{* *}$ & \\
\hline$v_{H}$ & & & & & $>35^{* *}$ & \\
\hline $\begin{array}{c}\text { LF } \\
\text {. }\end{array}$ & -3029.9 & & -3032.1 & & -3030.5 & \\
\hline $\begin{array}{l}\text { Param } \\
\text { AICC }\end{array}$ & $\begin{array}{c}21 \\
6103.3\end{array}$ & & $\begin{array}{c}20 \\
6105.5\end{array}$ & & $\begin{array}{c}20 \\
6102.3\end{array}$ & \\
\hline
\end{tabular}

* Significant at the $5 \%$ level.

LF is the maximized log likelihood function

Number of Param. is the number of estimated parameters.

AICC is the Akaike Information criterion adjunted for small sample bias $=$

$-2 \mathrm{LF}+2 \mathrm{~K}+2 \mathrm{~K}(\mathrm{~K}+1) /(\mathrm{n}-\mathrm{K}-1)$, where $\mathrm{K}=$ Number of Param, and $\mathrm{n}$ is the sample size.

** Degrees of freedom higher than 35. Normal copula was estimated for that state. 


\section{Table 14: Bivariate Results. Mexico-Argentina}

The first column estimates the Normal copula with switching parameter. $\rho_{\mathrm{L}}$ is the correlation coefficient in the low volatility state, is the correlation coefficient in the high volatility state. The second column gives estimates for the Normal copula with constant correlation. Standard errors are on the right of each column.

\begin{tabular}{c|cc|cc}
\hline & & & & \\
& Mixture Switching & Std Error & Mixture Constant & Std Error \\
\hline$\rho_{L}$ & $\mathbf{0 . 3 7 8}$ & $\mathbf{0 . 0 3 5 ^ { * }}$ & & \\
$\rho_{H}$ & $\mathbf{0 . 4 9 5}$ & $\mathbf{0 . 0 7 8 ^ { * }}$ & $\mathbf{0 . 3 9 4}$ & $\mathbf{0 . 0 3 3 ^ { * }}$ \\
& & & & \\
g_A & 3.659 & $0.515^{*}$ & 3.574 & $0.388^{*}$ \\
a0_A & 2.038 & $0.195^{*}$ & 2.029 & $0.185^{*}$ \\
a1_A & 0.072 & 0.045 & 0.068 & 0.042 \\
v_A & 14.512 & $7.350^{*}$ & 15.087 & $7.870^{*}$ \\
mu_A & 0.085 & 0.061 & 0.084 & 0.059 \\
phi_A & 0.073 & $0.037^{*}$ & 0.074 & $0.036^{*}$ \\
& & & & $3.390^{*}$ \\
g_M & 13.788 & $3.505^{*}$ & 12.976 & $0.205^{*}$ \\
a0_M & 1.997 & $0.208^{*}$ & 2.010 & $0.055^{*}$ \\
a1_M & 0.209 & $0.060^{*}$ & 0.213 & $0.996^{*}$ \\
v_M & 5.164 & $1.023^{*}$ & 5.142 & 0.049 \\
mu_M & 0.026 & 0.053 & 0.026 & $0.038^{*}$ \\
phi_M & 0.163 & $0.037^{*}$ & 0.165 & \\
\hline LF & $\mathbf{- 3 0 3 0 . 5}$ & & $\mathbf{3 0 3 1 . 4}$ & \\
p-value & $\mathbf{0 . 1 8 0}$ & & & \\
& & & $\mathbf{1 8}$ & \\
\hline Number of Param & $\mathbf{1 9}$ & & & \\
\hline & & & & \\
\hline
\end{tabular}

* Significant at the 5\% level.

LF is the maximized likelihood function

p-value LR test (1 degree of freedom).

Number of Param. is the number of estimated parameters. 


\section{Table 15: Bivariate Results. Mexico-Brazil: Estimation of Copula Models}

The first column gives estimates for the Mixture (Frank, Clayton-Gumbel). $\pi_{\mathrm{L}}$ is the weight of the Clayton copula in the low volatility state, $\pi_{\mathrm{H}}$ is the weight of the Clayton copula in the high volatility state. Lower tail dependence increases with $\pi . \theta$ and $\delta$ are the parameters of the Clayton and Gumbel copulas, respectively. The second column gives estimates for the Frank Switching model. $\alpha_{\mathrm{L}}$ is the parameter of the Frank copula in the low variance state. $\alpha_{H}$ is the parameter of the Frank copula in the high variance state. Dependence increases with $\alpha$. The third column gives estimates for the switching Student t copula. $\rho_{\mathrm{L}}$ and $\rho_{\mathrm{H}}$, and $v_{\mathrm{L}}$ and $v_{\mathrm{H}}$ are the correlation coefficients and the degrees of freedom in the low and high variance states respectively. Standard errors are on the right of each column. Only the copula parameters are shown.

\begin{tabular}{|c|c|c|c|c|c|c|}
\hline & $\begin{array}{c}\text { Mixture } \\
\text { Switching }\end{array}$ & Std Error & $\begin{array}{c}\text { Frank } \\
\text { Switching }\end{array}$ & Std Error & $\begin{array}{l}\text { Student t } \\
\text { Switching }\end{array}$ & Std Error \\
\hline$\pi_{L}$ & 0.034 & 0.065 & & & & \\
\hline$\pi_{H}$ & 0.329 & 0.191 & & & & \\
\hline$\theta$ & 1.965 & 2.726 & & & & \\
\hline$\delta$ & 1.106 & $0.279^{*}$ & & & & \\
\hline$\alpha$ & 1.075 & $0.356^{*}$ & & & & \\
\hline$\alpha_{L}$ & & & 1.180 & $0.242^{*}$ & & \\
\hline$\alpha_{H}$ & & & 2.890 & $0.737^{*}$ & & \\
\hline$\rho_{L}$ & & & & & 0.197 & $0.041^{*}$ \\
\hline$\rho_{H}$ & & & & & 0.412 & $0.086^{*}$ \\
\hline$v_{L}$ & & & & & $>35$ & \\
\hline$v_{H}$ & & & & & $>35$ & \\
\hline $\begin{array}{c}\text { LF } \\
\text { Number of }\end{array}$ & -3550.0 & & -3551.5 & & -3550.9 & \\
\hline $\begin{array}{l}\text { Param } \\
\text { AICC }\end{array}$ & $\begin{array}{c}22 \\
7145.3\end{array}$ & & $\begin{array}{c}19 \\
7142.0\end{array}$ & & $\begin{array}{c}19 \\
7140.8\end{array}$ & \\
\hline
\end{tabular}

* Significant at the 5\% level.

LF is the maximized log likelihood function

Number of Param. is the number of estimated parameters.

AICC is the Akaike Information criterion adjunted for small sample bias =

$-2 L F+2 K+2 K(K+1) /(n-K-1)$, where $K=$ Number of Param, and $n$ is the sample size. 


\section{Table 16: Bivariate Results. Mexico-Brazil}

The first column estimates the Normal copula with switching parameter. $\rho_{\mathrm{L}}$ is the correlation coefficient in the low volatility state, is the correlation coefficient in the high volatility state. The second column gives estimates for the Normal copula with constant correlation. Standard errors are on the right of each column.

\begin{tabular}{|c|c|c|c|c|}
\hline & Mixture Switching & Std Error & Mixture Constant & Std Error \\
\hline$\rho_{L}$ & 0.197 & $0.041^{*}$ & & \\
\hline$\rho_{H}$ & 0.412 & $0.086 *$ & 0.230 & $0.037 *$ \\
\hline g_A & 3.606 & $0.579 *$ & 3.576 & $0.552 *$ \\
\hline a0_A & 6.029 & $0.782 *$ & 5.847 & $0.745^{*}$ \\
\hline a1_A & 0.030 & 0.053 & 0.032 & 0.053 \\
\hline v_A & 12.188 & $5.805^{*}$ & 12.762 & $5.940 *$ \\
\hline $\mathrm{Mu} \_\mathrm{A}$ & 0.175 & 0.113 & 0.166 & 0.113 \\
\hline Phi_A & 0.061 & $0.037^{*}$ & 0.066 & $0.036^{*}$ \\
\hline g_M & 14.394 & $3.679 *$ & 13.417 & $3.314 *$ \\
\hline $\mathrm{a} 0 \_\mathrm{M}$ & 1.936 & $0.204^{*}$ & 1.956 & $0.211^{*}$ \\
\hline a1_M & 0.217 & $0.066^{*}$ & 0.218 & $0.070^{*}$ \\
\hline v_M & 5.384 & $1.093^{*}$ & 5.294 & $1.014^{*}$ \\
\hline $\mathrm{Mu} \_\mathrm{M}$ & 0.017 & 0.052 & 0.014 & 0.053 \\
\hline Phi_M & 0.186 & $0.038^{*}$ & 0.184 & $0.038^{*}$ \\
\hline$\underset{\text { p-value }}{\mathbf{L F}}$ & $\begin{array}{c}-3550.9 \\
0.028\end{array}$ & & -3553.3 & \\
\hline Number of Param & 19 & & 18 & \\
\hline & & & & \\
\hline \multicolumn{5}{|c|}{$\begin{array}{l}\text { * Significant at the } 5 \% \text { level. } \\
\text { LF is the maximized likelihood function } \\
\text { p-value LR test ( } 1 \text { degree of freedom). } \\
\text { Number of Param. is the number of estimate }\end{array}$} \\
\hline
\end{tabular}




\section{Table 17: Bivariate Results. Mexico-Chile. Estimation of Copula Models}

The first column gives estimates for the Mixture (Frank, Clayton,Gumbel). $\pi_{\mathrm{L}}$ is the weight of the Clayton copula in the low volatility state, $\pi_{\mathrm{H}}$ is the weight of the Clayton copula in the high volatility state. Lower tail dependence increases with $\pi . \theta$ and $\delta$ are the parameters of the Clayton and Gumbel copulas, respectively. The second column gives estimates for the Frank Switching model. $\alpha_{\mathrm{L}}$ is the parameter of the Frank copula in the low variance state. $\alpha_{H}$ is the parameter of the Frank copula in the high variance state. Dependence increases with $\alpha$. Standard errors are on the right of each column. Only the copula parameters are shown.

\begin{tabular}{|c|c|c|c|c|c|c|c|c|}
\hline & $\begin{array}{c}\text { Mixture } \\
\text { Switching }\end{array}$ & Std Error & $\begin{array}{c}\text { Mixture } \\
\text { Switching } \\
\alpha=0 \\
\end{array}$ & & $\begin{array}{c}\text { Frank } \\
\text { Switching } \\
\end{array}$ & Std Error & $\begin{array}{c}\text { Student t } \\
\text { Switching }\end{array}$ & Std Error \\
\hline$\pi_{C L}$ & 0.095 & 0.070 & 0.103 & $0.059^{*}$ & & & & \\
\hline$\pi_{G L}$ & 0.366 & 0.270 & 0.401 & $0.188^{*}$ & & & & \\
\hline$\pi_{C H}$ & 0.000 & (See text) & 0.000 & (See text) & & & & \\
\hline$\pi_{G H}$ & 1.000 & (See text) & 1.000 & (See text) & & & & \\
\hline$\theta$ & 2.979 & $1.553^{*}$ & 2.801 & $1.554^{*}$ & & & & \\
\hline$\delta$ & 1.272 & $0.102 *$ & 1.268 & $0.094 *$ & & & & \\
\hline$\alpha$ & 0.202 & 0.906 & & & & & & \\
\hline$\alpha_{L}$ & & & & & 1.155 & 0.991 & & \\
\hline$\alpha_{H}$ & & & & & 3.543 & $0.641 *$ & & \\
\hline$\rho_{L}$ & & & & & & & 0.234 & $0.043^{*}$ \\
\hline$\rho_{H}$ & & & & & & & 0.374 & $0.078^{*}$ \\
\hline$v_{L}$ & & & & & & & $>35$ & \\
\hline$v_{H}$ & & & & & & & $>35$ & \\
\hline $\begin{array}{c}\text { LF } \\
\text { Number of } \\
\text { Param } \\
\text { AICC }\end{array}$ & $\begin{array}{c}-2704.7 \\
\\
22 \\
5454.7\end{array}$ & & $\begin{array}{c}-2704.8 \\
\\
21 \\
5452.8\end{array}$ & & $\begin{array}{c}-2718.7 \\
19 \\
5476.2\end{array}$ & & $\begin{array}{c}-2707.6 \\
19 \\
5454.2\end{array}$ & \\
\hline
\end{tabular}

* Significant at the 5\% level.

LF is the maximized log likelihood function

Number of Param. is the number of estimated parameters.

AICC is the Akaike Information criterion adjunted for small sample bias =

$-2 \mathrm{LF}+2 \mathrm{~K}+2 \mathrm{~K}(\mathrm{~K}+1) /(\mathrm{n}-\mathrm{K}-1)$, where $\mathrm{K}=$ Number of Param, and $\mathrm{n}$ is the sample size. 


\section{Table 18: Bivariate Results. Mexico-Chile}

The first column estimates the Mixture (Frank, Clayton, Gumbel). $\pi_{\mathrm{CL}}$ is the weight of the Clayton copula in the low volatility state, $\pi_{\mathrm{CH}}$ is the weight of the Clayton copula in the high volatility state. ). $\pi_{\mathrm{CL}}$ is the weight of the Clayton copula in the low volatility state, $\pi_{\mathrm{CH}}$ is the weight of the Clayton copula in the high

volatility state. Lower tail dependence increases with $\pi_{\mathrm{C}}$. Lower tail dependence increases with $\pi_{\mathrm{G}} . \theta, \delta$ and $\alpha$ are the parameters of the Clayton, Gumbel, and Frank copulas, respectively. The third column gives estimates for the constant weight mixture. Standard errors are on the right of each column.

\begin{tabular}{|c|c|c|c|c|c|c|}
\hline & $\begin{array}{c}\text { Mixture } \\
\text { Switching }\end{array}$ & Std Error & $\begin{array}{c}\text { Mixture } \\
\text { Switching } \\
\alpha=0\end{array}$ & & $\begin{array}{l}\text { Mixture } \\
\text { Constant }\end{array}$ & Std Error \\
\hline$\pi_{C L}$ & 0.095 & 0.070 & 0.103* & 0.059* & & \\
\hline$\pi_{G L}$ & 0.366 & 0.270 & $0.401 *$ & 0.188* & & \\
\hline$\pi_{C H}$ & 0.000 & (See text) & 0.000 & (See text) & 0.143 & $0.051 *$ \\
\hline$\pi_{G H}$ & 1.000 & (See text) & 1.000 & (See text) & 0.857 & $0.051 *$ \\
\hline$\theta$ & 2.979 & $1.553 *$ & $2.801 *$ & $1.554 *$ & 1.595 & $0.201 *$ \\
\hline$\delta$ & 1.272 & $0.102 *$ & $1.268 *$ & $0.094 *$ & 1.128 & $0.034 *$ \\
\hline$\alpha$ & 0.202 & 0.906 & $\mathbf{0 . 0 0 0}$ & & & \\
\hline g_C & 3.318 & $0.706^{*}$ & 3.308 & $0.525^{*}$ & 3.357 & $0.590 *$ \\
\hline $\mathrm{a} 0 \_\mathrm{C}$ & 0.499 & $0.089 *$ & 0.500 & $0.072 *$ & 0.495 & $0.084 *$ \\
\hline al_C & 0.255 & $0.058^{*}$ & 0.255 & $0.055^{*}$ & 0.227 & $0.057^{*}$ \\
\hline v_C & 9.068 & $1.003 *$ & 8.955 & $3.044 *$ & 8.992 & $0.836^{*}$ \\
\hline mu_C & 0.071 & $0.006^{*}$ & 0.070 & $0.036^{*}$ & 0.074 & $0.037^{*}$ \\
\hline phi_C & 0.154 & $0.047 *$ & 0.155 & $0.040 *$ & 0.151 & $0.018^{*}$ \\
\hline g_M & 11.760 & $0.998^{*}$ & 11.720 & $1.113^{*}$ & 12.080 & $0.604^{*}$ \\
\hline a0_M & 1.851 & $0.126^{*}$ & 1.853 & $0.152^{*}$ & 1.877 & $0.142 *$ \\
\hline a1_M & 0.095 & $0.044^{*}$ & 0.095 & $0.045^{*}$ & 0.096 & $0.052^{*}$ \\
\hline v_M & 6.279 & $1.014 *$ & 6.261 & $1.133^{*}$ & 6.038 & $0.795^{*}$ \\
\hline mu_M & 0.021 & 0.058 & 0.021 & 0.052 & 0.020 & 0.052 \\
\hline phi_M & 0.180 & $0.019 *$ & 0.180 & $0.035^{*}$ & 0.178 & $0.035^{*}$ \\
\hline $\begin{array}{c}\text { LF } \\
\text { p-value }\end{array}$ & -2704.7 & & $\begin{array}{c}-2704.8 \\
0.1797\end{array}$ & & -2705.7 & \\
\hline $\begin{array}{c}\text { Number of } \\
\text { Param }\end{array}$ & 22 & & 21 & & 20 & \\
\hline
\end{tabular}

* Significant at the 5\% level.

LF is the maximized likelihood function, p-value LR test (1 degree of freedom).

Number of Param. is the number of estimated parameters. 
Table 19: Summary of Results: Latin-American Case (generator: Mexico)

\begin{tabular}{lccc}
\hline & $\begin{array}{c}\text { Argentina } \\
\text { (Student) }\end{array}$ & $\begin{array}{c}\text { Brazil } \\
\text { (Student) }\end{array}$ & $\begin{array}{c}\text { Chile } \\
\text { (Fra,Cla,Gu) }\end{array}$ \\
\hline $\begin{array}{l}\text { Nependence } \\
\uparrow \text { Tail Dependence }\end{array}$ & No & Yes & No \\
& No & No & 0.134 \\
$\tau_{L}$ (Empirical) & 0.238 & 0.120 & 0.297 \\
$\tau_{H}$ (Empirical) & 0.372 & 0.268 & $0.145^{*}$ \\
$\tau_{L}$ (Estimated) & $0.247^{*}$ & & $0.211^{*}$ \\
$\tau_{H}$ (Estimated) & $0.330^{*}$ & 0.126 & $0.008^{*}$ \\
\hline$\lambda_{L}$ (Low Variance) & & 0.270 & $0.000^{*}$ \\
$\lambda_{L}$ (HighVariance) & 0.000 & & \\
& 0.000 & 0.000 & $0.109^{*}$ \\
$\lambda_{U}$ (Low Variance) & & 0.000 & $0.273^{*}$ \\
$\lambda_{U}$ (HighVariance) & 0.000 & & \\
\hline
\end{tabular}

$\tau_{\mathrm{i}}$ is Kendall's tau in state $\mathrm{i}(\mathrm{i}=$ Low, High)

$\lambda \mathrm{j}$ is the tail probability in the Low/High variance state $(\mathrm{j}=$ Lower, Upper $)$

* These values were not found significantly different from each other. 


\section{Figure 1. Simulated Copulas}

Scatter plots of simulated Gumbel, Clayton, Frank, and Student Copulas. All marginal are standardized normals. The parameter of the copulas were chosen to give a Kendall's tau equal to 0.3 .
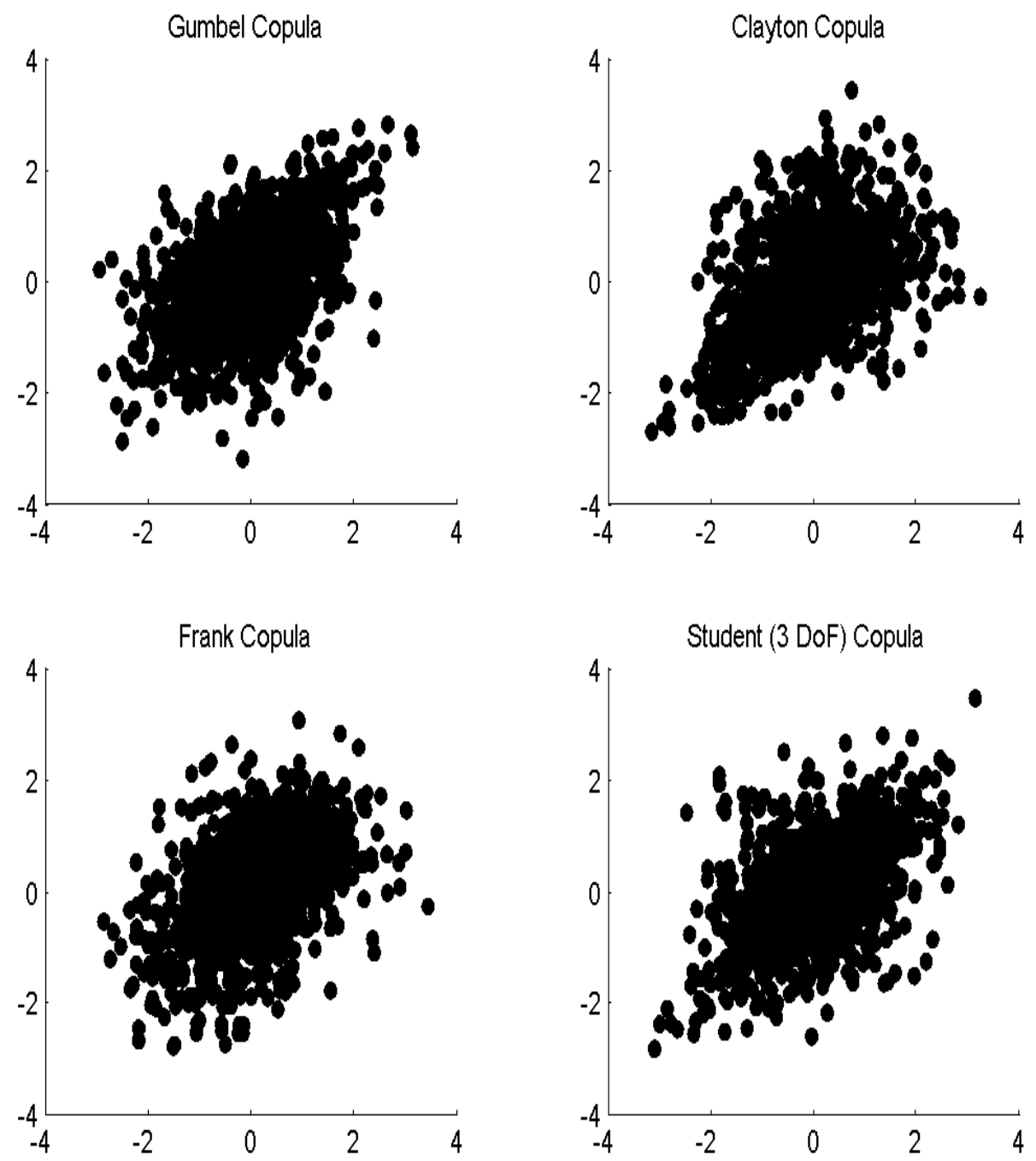
Figure 2: Asian Markets Returns
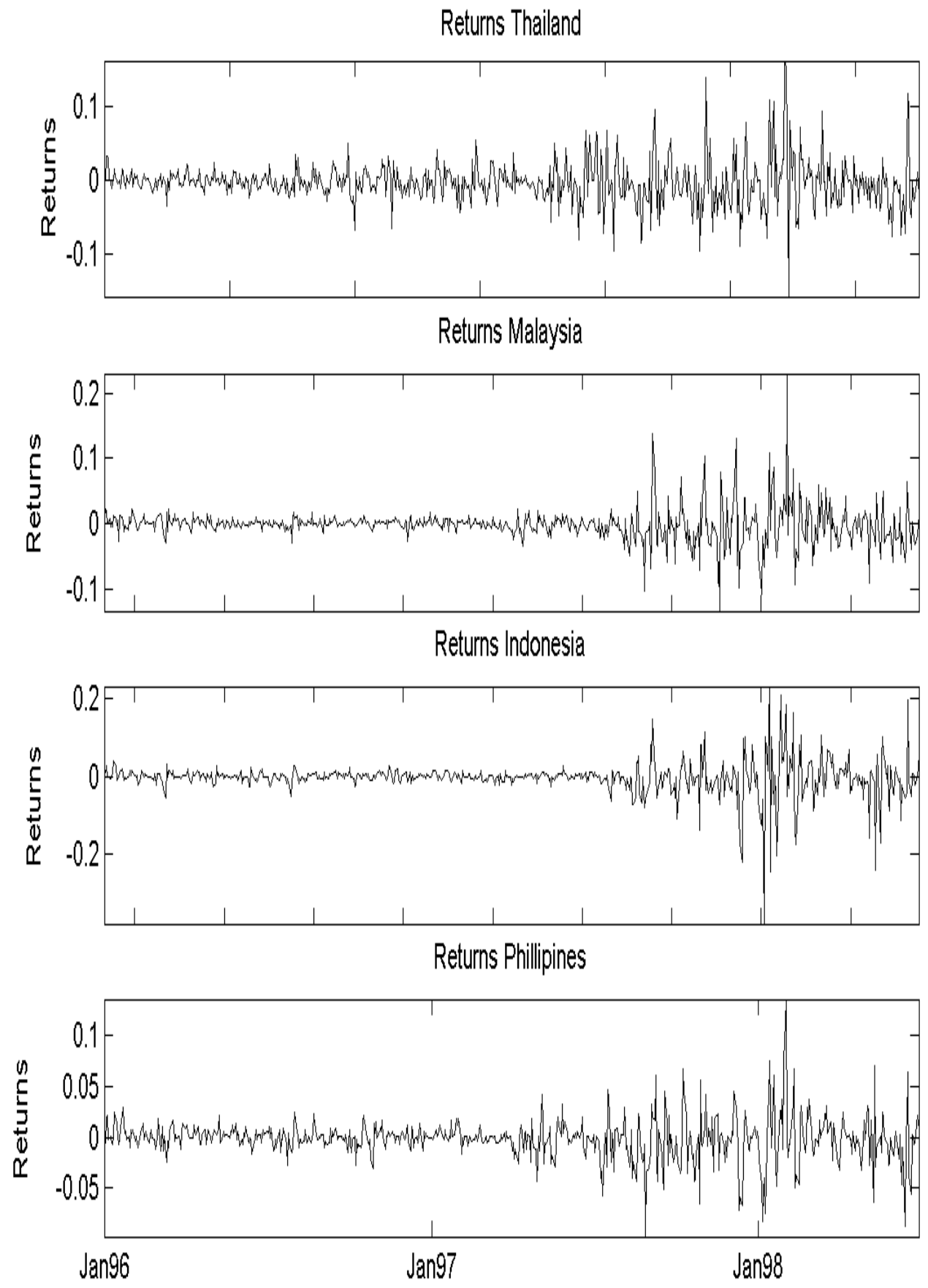
Figure 3: Smooth Probabilities. High Volatility State
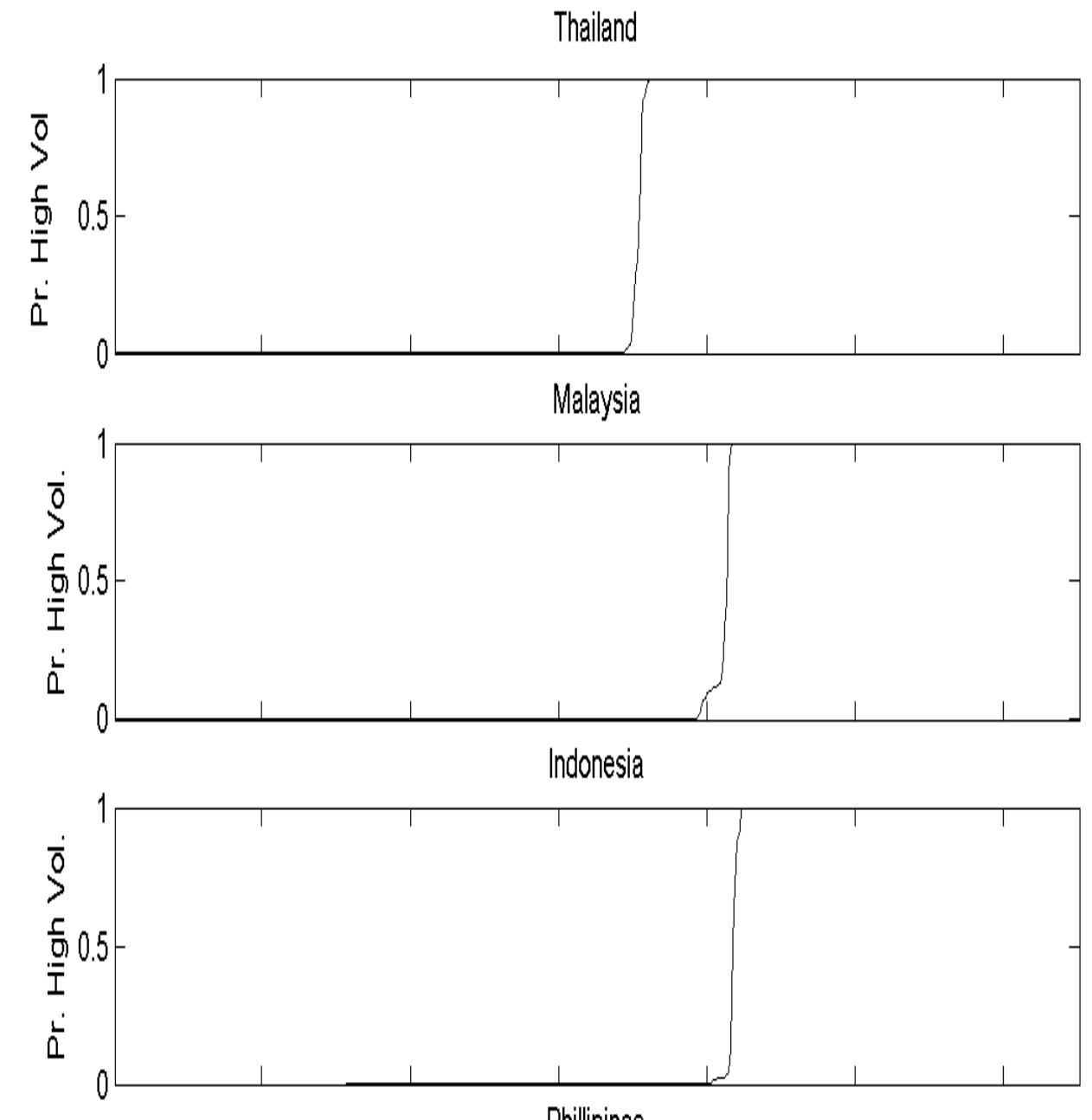

Phillipines

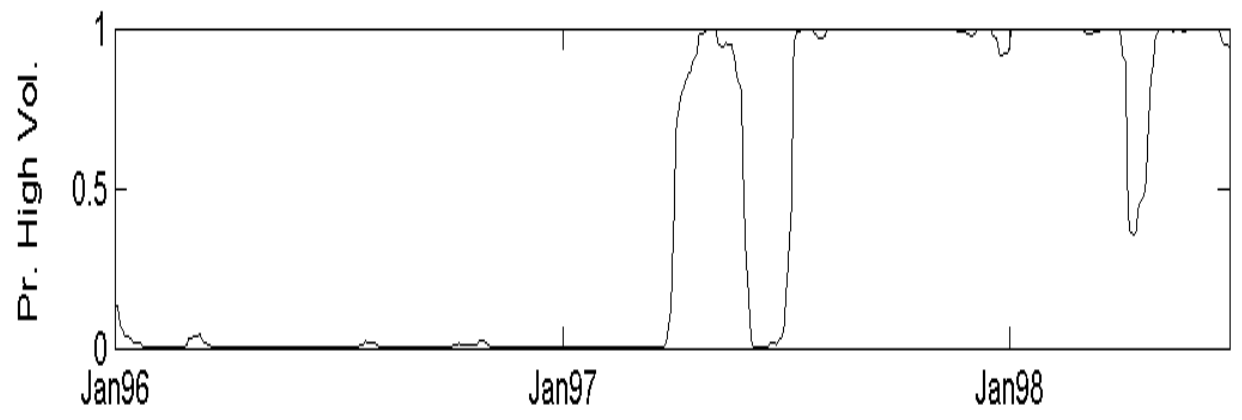


Figure 4: Latin-American Market Returns

Mexico
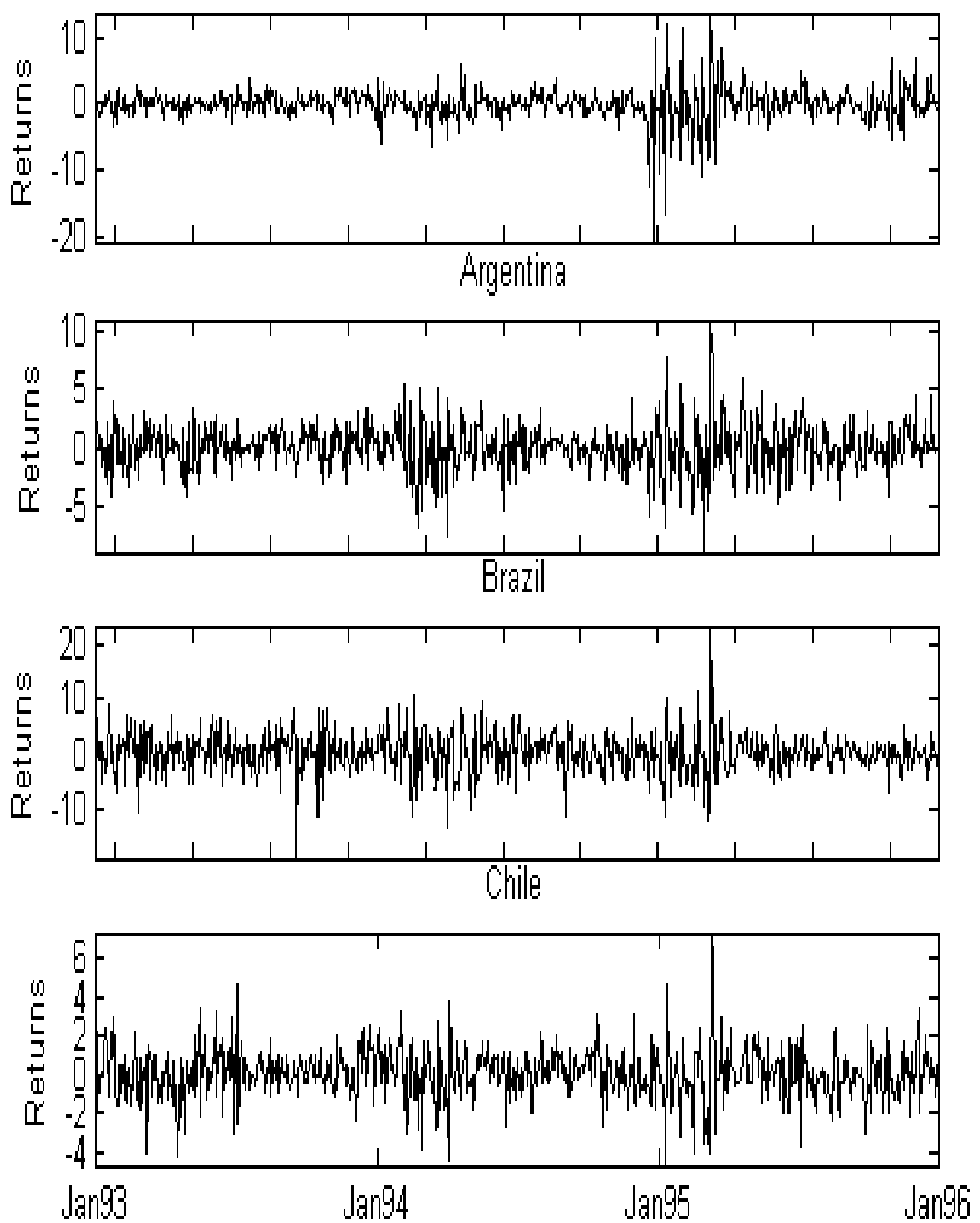
Figure 5: Smooth Probabilities. High Volatility State (Latin-America)

Mexico
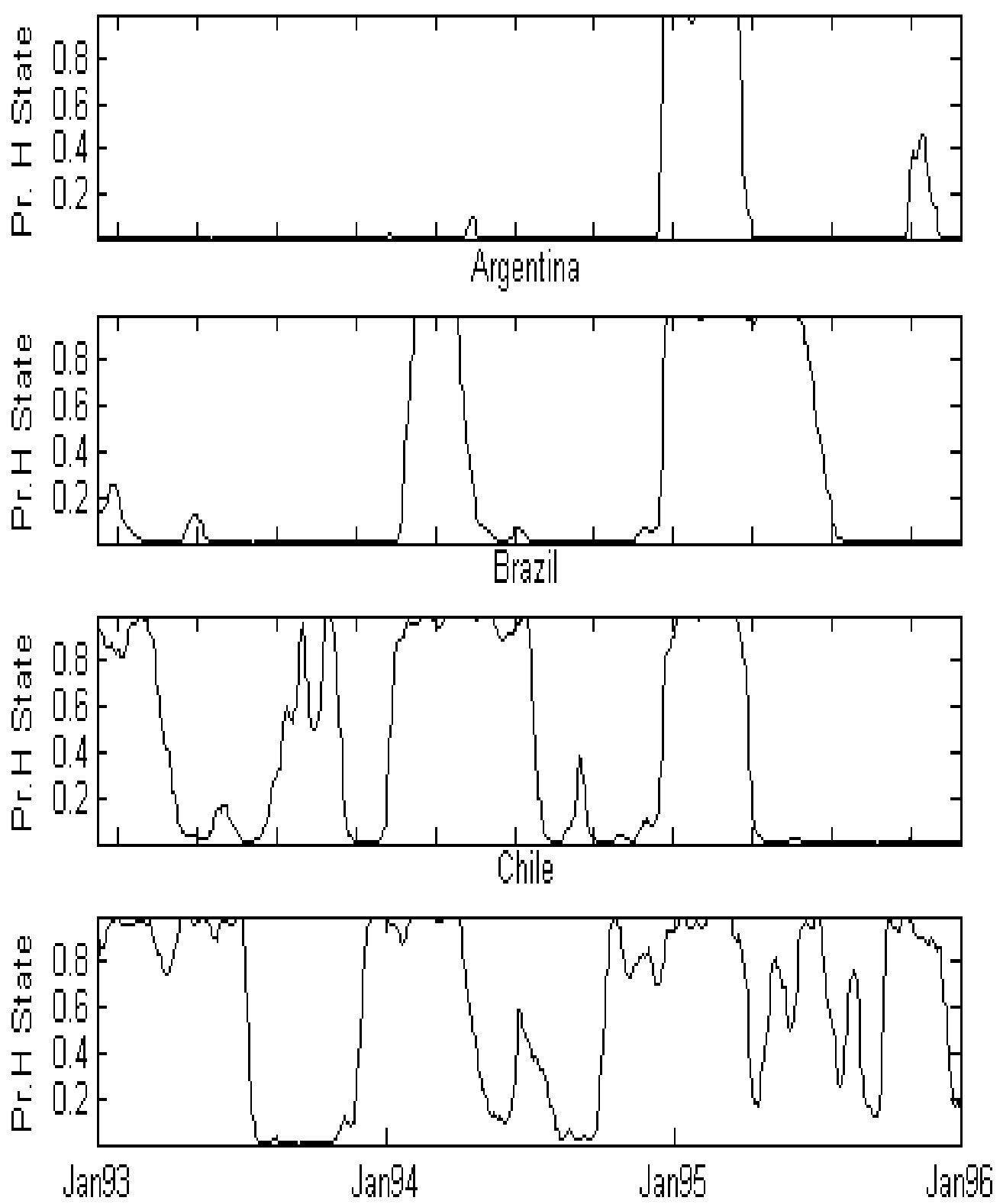


\section{APPENDIX. Specification tests for the copulas}

If $C(u, v)$ is a copula, where $u=F(x)$ and $v=G(y)$, it is a well known result $^{35}$ that the conditional distribution of $Y \mid X=x$ :

$$
H_{Y \mid X}(y \mid x)=C_{1}(F(x), G(y))
$$

where:

$$
C_{1}(u, v)=\frac{\partial C(u, v)}{\partial u}
$$

is uniformly distributed in $(0,1)$. This suggests testing the adequacy of the copula specification by testing its first derivative with respect to each of its arguments. In this Appendix I use two tests that are standard in the literature on $\operatorname{copulas}^{36}$ : a Kolmogorov-Smirnov test, and a graphical test that employs a QQ-plot of $C_{1}(u, v)$ against standard uniform quantiles. This QQ-plot should give a straight line if the copula is well specified.

In performing the tests it must be noted that the typical copula we are dealing with in this paper is a mixture of conditional copulas ${ }^{37}$, and therefore a copula:

$$
C\left(u_{t}, v_{t} \mid I_{t-1}\right)=\sum_{S_{t}} \sum_{S_{t-1}} C\left(u_{t}, v_{t} \mid S_{t}, S_{t-1}, I_{t-1}\right) I P\left(S_{t} \mid S_{t-1}\right) I P\left(S_{t-1} \mid I_{t-1}\right),
$$

where the $I P\left(S_{t} \mid S_{t-1}\right) \mathrm{s}$ are constants from the matrix of transition probabilities, and the $I P\left(S_{t-1} \mid I_{t-1}\right) \mathrm{s}$ are the filtered probabilities. The tests are performed on the best fitting copulas (see tables 4 to 19), and shown in table A1 (Kolmogorov-Smirnov tests) and in Figures A1-A3 (QQ-plots). In table A1 and figures A1-A3 $v$ is the transformed residual of the generator country, while $u$ is the transformed residual of the receiving country. Note that the tests are performed both ways (that is, testing $u \mid v$ and $v \mid u$ ). Both the Kolmogorov-Smirnov tests and the QQ-plot show that the quality of the fit is quite good, suggesting that the copulas are well specified.

\footnotetext{
${ }^{35}$ See Klugman and Parsa (1999).

${ }^{36}$ See Klugman and Parsa, and also Breymann et al. (2003).

${ }^{37}$ The theory of conditional copulas is developed in Patton (2001a, 2001b).
} 


\section{Table A1. Kolmogorov-Smirnov tests:}

In table A1 $v$ is the transformed residual of the generator country, while $u$ is the transformed residual of the receiving country. Note that the tests are performed both ways (that is, testing $\mathrm{u} \mid \mathrm{v}$ and $\mathrm{v} \mid \mathrm{u}$ ). In the Asian case, the generator country in Thailand, in the Latin-American case the generator country is Mexico. An entry lower than 0.05 indicates rejection of the hypothesis that the conditional copula is standard uniform.

\begin{tabular}{c|c|c}
\hline & $\mathrm{C}(\mathrm{u} \mid \mathrm{v})$ & $\mathrm{C}(\mathrm{v} \mid \mathrm{u})$ \\
\hline Malaysia & 0.090 & 0.333 \\
Indonesia & 0.441 & 0.759 \\
Korea & 0.881 & 0.628 \\
Philippines & 0.919 & 0.657 \\
\hline Argentina & & 0.561 \\
Brazil & 0.999 & 0.821 \\
Chile & 0.930 & 0.886 \\
\hline
\end{tabular}


Figure A1. QQ-plots. Asian case:

In Figure A $1 v$ is the transformed residual of the generator country, while $u$ is the transformed residual of the receiving country. Note that the tests are performed both ways (that is, testing $\mathrm{u} \mid \mathrm{v}$ and $\mathrm{v} \mid \mathrm{u}$ ). In the Asian case, the generator country in ThailandThe graphical test employs a QQ-plot of C(u|v) and $\mathrm{C}(\mathrm{v} \mid \mathrm{u})$ against standard uniform quantiles. This QQ-plot should give a straight line if the copula is well specified.
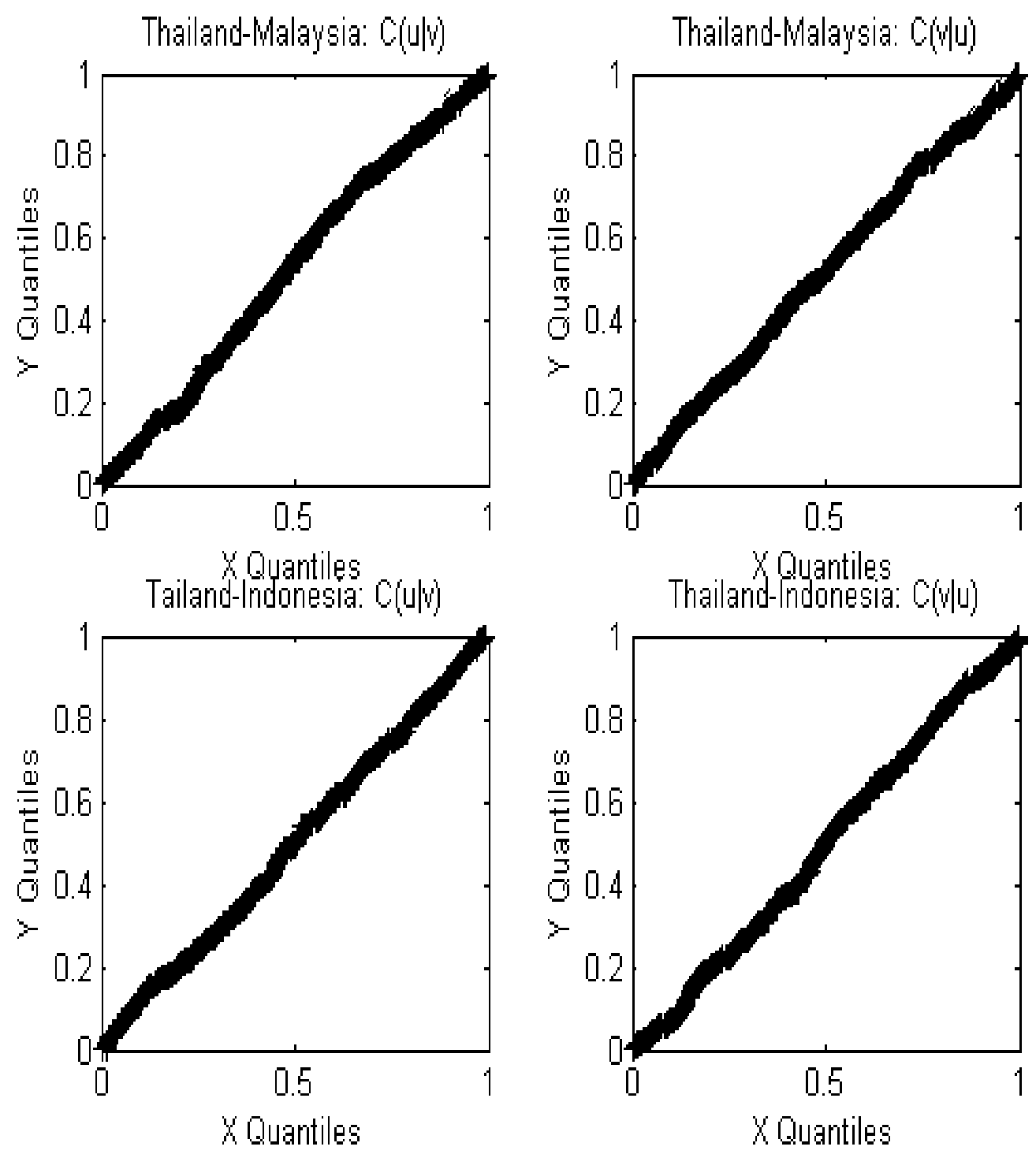
Figure A2. QQ-plots. Asian case:

In Figure A2 $v$ is the transformed residual of the generator country, while $u$ is the transformed residual of the receiving country. Note that the tests are performed both ways (that is, testing $\mathrm{u} \mid \mathrm{v}$ and $\mathrm{v} \mid \mathrm{u}$ ). In the Asian case, the generator country in Thailand. The graphical test employs a QQ-plot of C(ulv) and $\mathrm{C}(\mathrm{v} \mid \mathrm{u})$ against standard uniform quantiles. This QQ-plot should give a straight line if the copula is well specified.
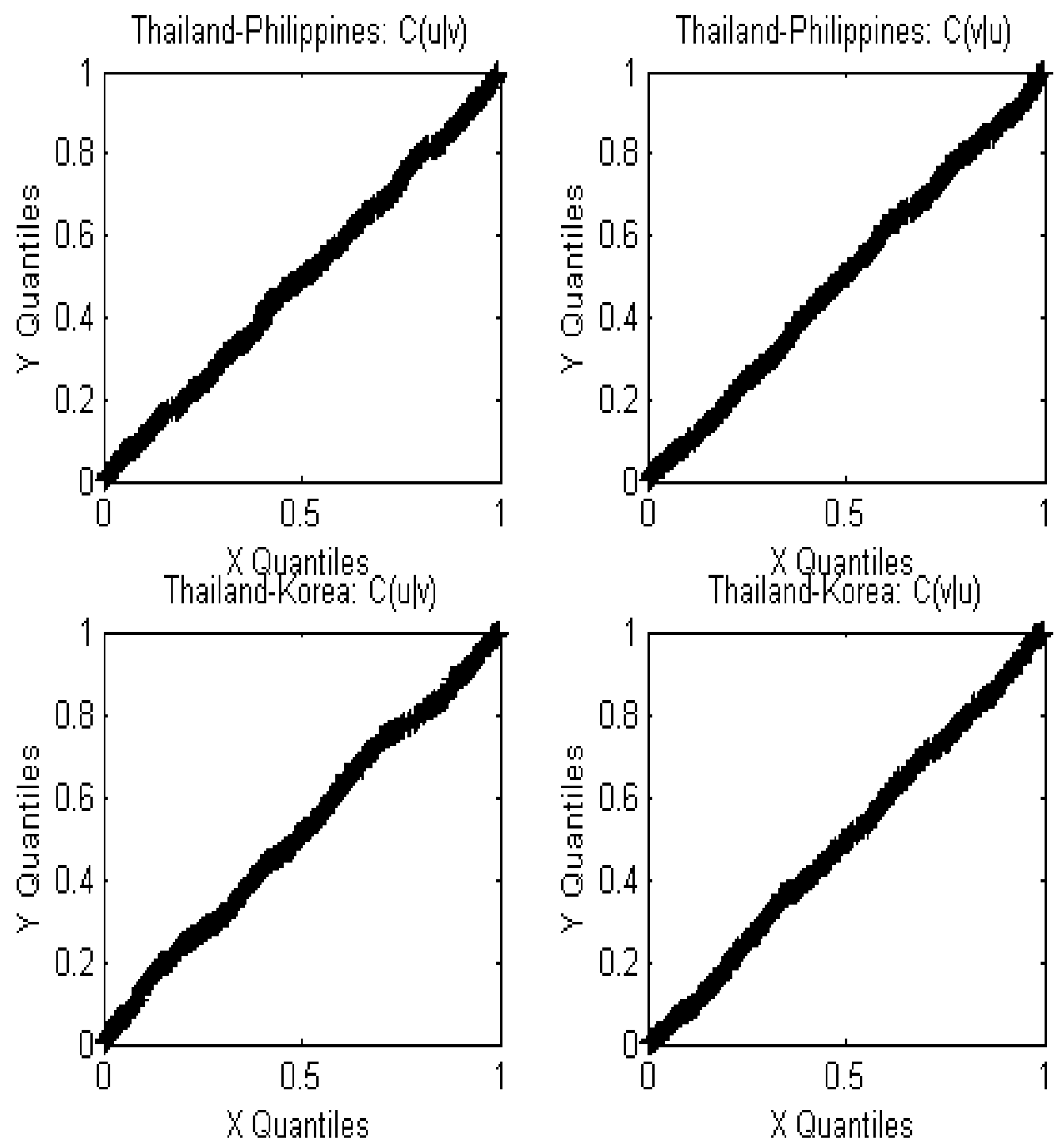


\section{Figure A3. QQ-plots. Mexican case:}

In Figure A3 $v$ is the transformed residual of the generator country, while $u$ is the transformed residual of the receiving country. Note that the tests are performed both ways (that is, testing $\mathrm{u} \mid \mathrm{v}$ and $\mathrm{v} \mid \mathrm{u}$ ). In the Latin-American case the generator country is Mexico. The graphical test employs a QQ-plot of $\mathrm{C}(\mathrm{u} \mid \mathrm{v})$ and $\mathrm{C}(\mathrm{v} \mid \mathrm{u})$ against standard uniform quantiles. This QQ-plot should give a straight line if the copula is well specified.
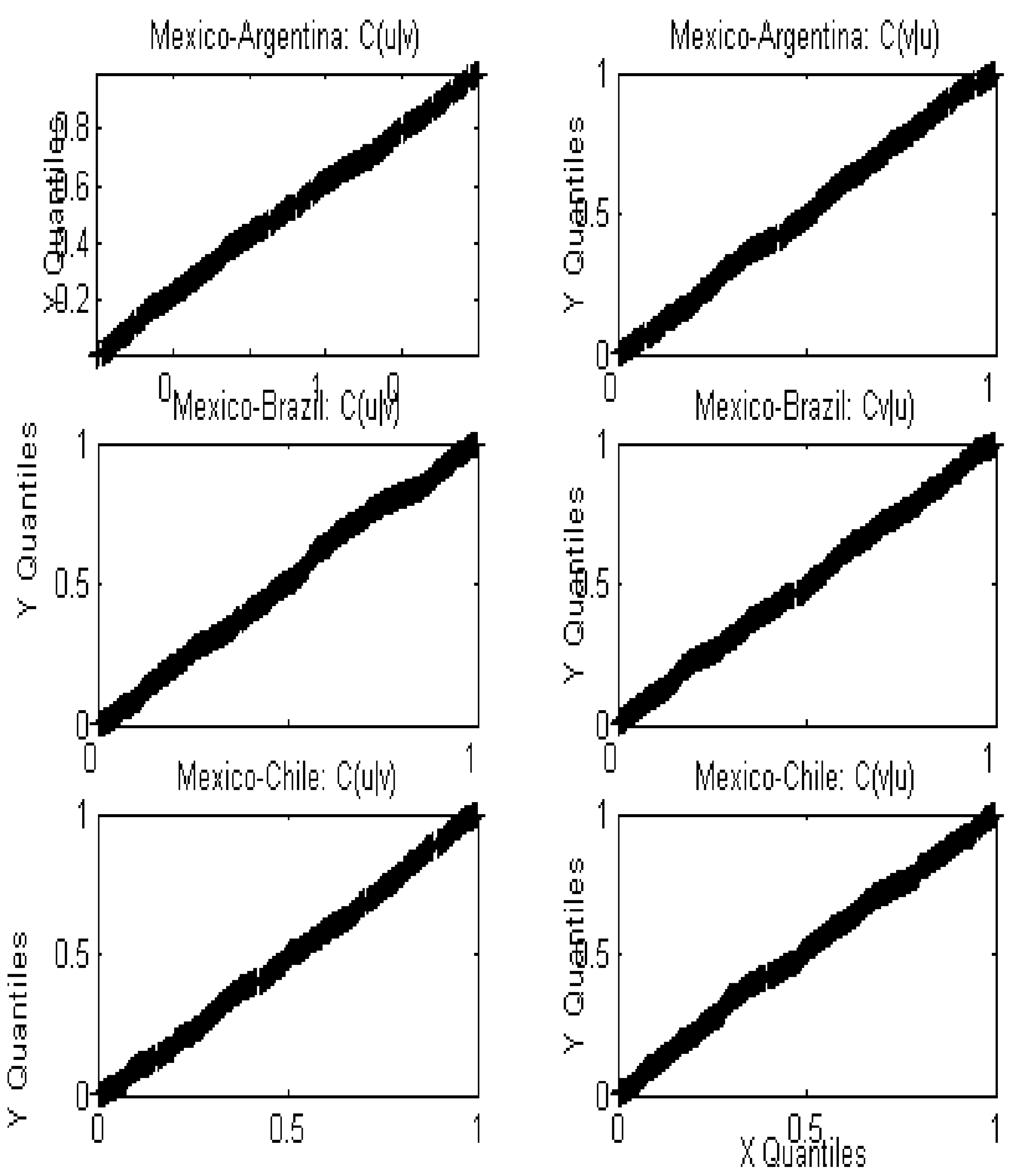